NBER WORKING PAPER SERIES

\title{
EFFECT OF PRESCRIPTION OPIOIDS AND PRESCRIPTION OPIOID CONTROL POLICIES ON INFANT HEALTH
}

\author{
Engy Ziedan \\ Robert Kaestner \\ Working Paper 26749 \\ http://www.nber.org/papers/w26749
NATIONAL BUREAU OF ECONOMIC RESEARCH
1050 Massachusetts Avenue
Cambridge, MA 02138 \\ February 2020, Revised November 2020
}

We thank Dhaval Dave and Abraham Asfaw for their help obtaining data used in the article. The views expressed herein are those of the authors and do not necessarily reflect the views of the National Bureau of Economic Research.

At least one co-author has disclosed additional relationships of potential relevance for this research. Further information is available online at http://www.nber.org/papers/w26749.ack

NBER working papers are circulated for discussion and comment purposes. They have not been peer-reviewed or been subject to the review by the NBER Board of Directors that accompanies official NBER publications.

(C) 2020 by Engy Ziedan and Robert Kaestner. All rights reserved. Short sections of text, not to exceed two paragraphs, may be quoted without explicit permission provided that full credit, including $(\odot$ notice, is given to the source. 
Effect of Prescription Opioids and Prescription Opioid Control Policies on Infant Health Engy Ziedan and Robert Kaestner

NBER Working Paper No. 26749

February 2020, Revised November 2020

JEL No. I12,I18,J1

\begin{abstract}
$\underline{\text { ABSTRACT }}$
Prescription opioid use among women of reproductive age and pregnant women is relatively common. In this article, we examine whether state opioid control policies affected prescription opioid use and, in turn, infant health and maternal behaviors. We conduct several types of analyses including reduced form analyses of the effect of state policies on infant health and maternal behaviors, and instrumental variables analyses of the effects of prescription opioid use on infant health and maternal behaviors. Results from our analysis suggest that reductions in prescription opioid use because of state prescription opioid control policies have improved infant health modestly at the population level with larger implied effects at the individual level.
\end{abstract}

Engy Ziedan

Department of Economics

School of Liberal Arts

Tulane University

206 Tilton Hall

6823 St. Charles Avenue

New Orleans, LA 70118

eziedan@tulane.edu

Robert Kaestner

Harris School of Public Policy

University of Chicago

1307 East 60th Street (Room 3057)

Chicago, IL 60637

and NBER

kaestner@uchicago.edu 


\section{Introduction}

Prescription opioid use during pregnancy is not uncommon. An analysis of Medicaid claims in 46 states from 2002 to 2007 found that $21 \%$ of women filled an opioid prescription while pregnant (Desai et al. 2014). A similar study of medical claims from a large, private insurer from 2005 to 2011 found that $14 \%$ of women had a prescription for an opioid during pregnancy (Bateman et al. 2014). More generally, the use of prescription opioids among pregnant women reflects the rate of prescription opioid use among women of reproductive age. Researchers from the CDC reported that for the period between 2008 and 2012 , on average, $39 \%$ of women of reproductive age covered by Medicaid and $28 \%$ of privately insured women had a prescription for an opioid during the year (Ailes et al. 2015). Finally, mis-use of prescription opioids among pregnant women is also non-trivial. Kozhimannil et al. (2017) analyzed a national sample of currently pregnant women between 2005 and $2104 ; 5 \%$ of the sample reported using a prescription opioid for non-medical purposes in the past year.

Consistent with the relatively high prevalence of prescription opioid use, and its increase over time, there has been a commensurate increase in opioid use disorder (OUD) among pregnant women and neonatal abstinence syndrome (NAS) among infants. The rate of OUD among pregnant women increased from 1.5 per 1000 in 1999 to 6.5 per 1000 in 2014 (Haight et al. 2018). There is also a substantial amount of state heterogeneity. For example, in Vermont the rate of OUD among pregnant women was 48.6 per 1000 in 2014. There has been a corresponding increase in NAS, which increased from 1.5 per 1000 in 2004 to 8 per 1000 in 2014 (Winkleman et al. 2018). Again, there is significant heterogeneity; the rate of NAS among births covered by Medicaid was 14 per 1000 in 2014.

While the medical use of prescription opioids during pregnancy has been studied and is generally considered safe, there are risks (FDA 2015; ACOG 2017). Primary among those risks is mis-use and addiction. However, most prescriptions for opioids during pregnancy are for less than 30 days, although multiple prescriptions during pregnancy are not uncommon (Desai et al. 2014). There are also risks associated with not providing prescription opioids during pregnancy (FDA 2015; ACOG 2017). Most prescriptions for opioids during pregnancy are for pain relief (e.g., back and migraine). Untreated pain 
can be debilitating and can cause anxiety, depression and stress (Fine 2011; Bushnell et al. 2013). The consequences of untreated pain can lead to biological and behavioral responses that may adversely affect the health of both the mother and fetus (infant), for example, greater alcohol use (Wiltkiewitz and Vowles 2018; Paulus et al. 2019). More importantly, it is not just opioid use during the pregnancy period that may affect health, but also pre-conception opioid use and mis-use. Pre-conception health, and health behaviors, are widely acknowledged as important determinants of pregnancy health and pregnancy outcomes (Johnson et al., 2006; American College of Obstetrics and Gynecology (ACOG) 2005; March of Dimes 2002).

Given the prevalence of prescription opioid use among women of reproductive age and during pregnancy, it is plausible that policies targeted at reducing prescription opioid use could have effects on infant health. Reductions in prescription opioid use among women of reproductive age may reduce misuse, abuse and OUD among pregnant women and, as a result, reduce NAS and improve infant health more broadly ${ }^{1}$. In particular, there are some demographic groups for which the beneficial effects may be more manifest, for example, among women (births) covered by Medicaid, as this group has relatively high rates of prescription opioid mis-use and abuse. On the other hand, reductions in prescription opioid use to treat pain prior to, and during pregnancy, which constitutes the large majority of prescription opioid use and is relatively safe, may adversely affect infant health. As noted, untreated pain may result in worse maternal mental health, greater use of other harmful substances to reduce pain (e.g., alcohol) and more stress, all of which may adversely affect infant health.

In this article, we examine these issues. We obtain estimates of the effects of prescription opioids and prescription opioid control policies on infant health (e.g., birth weight) and maternal behaviors (e.g., prenatal care and smoking). The control policies we focus on are prescription drug monitoring programs (PDMPs) and pill mill legislation, which have been shown to reduce prescription opioid use (Kaestner

\footnotetext{
${ }^{1}$ See Gihleb et al. (2020) who find that an operational PDMP reduced NAS by $10 \%$, but had no effect on other infant health outcomes. We discuss this study in our conclusions.
} 
and Ziedan 2019). Therefore, it is plausible that these policies have influenced infant health by reducing prescription opioid use among women of reproductive age and pregnant women.

We conduct several analyses. First, we exploit variation in the timing of the adoption of PDMPs and pill mill statutes to conduct a difference-in-differences analysis of the effect of these policies on prescription opioid use (first stage) and infant health and maternal behaviors (reduced form). ${ }^{2}$ Importantly, because prior research has shown that the effectiveness of PDMPs depends on features of a PDMP, we incorporate differences in PDMP attributes and allow different types of PDMPs to have different effects on outcomes of interest. Second, we implement an instrumental variables analysis in which we use the prescription opioid control policies to instrument for prescription opioid use. As part of this analysis, we also provide reduced form estimates of the effect of state policies on infant health and maternal behaviors.

Information on infant health and maternal behaviors comes from vital records (birth certificates) and information on prescription opioid use comes from the Automation of Reports and Consolidated Orders System (ARCOS). We obtain estimates separately for demographic groups stratified by age and marital status because of known differences in their rates of prescription opioid use and mis-use. For example, prescription opioid abuse is higher among younger women than older women and higher among women whose birth is covered by Medicaid than women whose births are covered by private insurance. ${ }^{3}$

Results from our analysis suggest that reductions in prescription opioid use, for example, because of state prescription opioid control policies, are associated with modest improvements in infant health at the population level and more significant improvements at the individual level. We show that the adoption of a "modern" PDMP or a pill mill law reduced prescription opioid sales by between $10 \%$ and $40 \%$ depending on the policy—pill mill laws tend to have larger effects—and types of prescription opioid (all

\footnotetext{
${ }^{2}$ Throughout the article we refer to prescription opioid use for ease of exposition, but we acknowledge that we measure prescription opioids sales.

${ }^{3}$ While we do not observe insurance coverage in all years of the data, we can identify reasonably accurately women on Medicaid using age and marital status. For example, among pregnant women age 18 to 25 and unmarried, $74 \%$ of births were covered by Medicaid.
} 
v. hydrocodone and oxycodone). IV estimates show that these policy-driven decreases in prescription opioid use are associated with significant improvements in infant birthweight: a 33\% decrease in prescription opioid use is associated with a 7 grams ( $1 \%$ of a standard deviation) increase in birthweight. These results represent population level effects that are driven by changes in prescription opioid use among approximately $20 \%$ of women of reproductive age and pregnant women. For women affected, state policies are likely to have had a more substantial impact on birthweight $(\approx 35$ grams $)$ and LBW $(\approx 0.5$ percentage points). We also find that prescription opioid use is associated with delayed prenatal care and inadequate prenatal care and that that state policies that reduce prescription opioid use result in improvements in these behaviors. We do not find any evidence of adverse effects of the reduction in prescription opioids on infant health suggesting that reductions in prescription opioid use due to state policies has not adversely affected infant health and maternal behaviors.

\section{Effects of PDMPs and Pill Mill Laws on Prescription Opioid Use}

Our research is predicated on the assumption that PDMPs and pill mill laws reduced prescription opioid use and that this decrease in prescription opioid use may influence infant health. This assumption is consistent with prior evidence. Recent reviews by Weiner et al. (2017) and Ponnapali et al. (2018) concluded that PDMPs have effectively reduced opioid prescriptions and the authors emphasized the point that it is particular features of a PDMP, such greater integration of the PDMP into electronic health records that are particularly effective.

There are several, quasi-experimental studies of the effect of PDMPs on opioid prescriptions that support the conclusions of Weiner et al. (2017). ${ }^{4}$ Bao et al. (2016) is a good example. It examined the effect of PDMPs on physician prescribing behavior using data from the National Ambulatory Medical

\footnotetext{
${ }^{4} \mathrm{We}$ focus on quasi-experimental studies. We do not review other types of studies because of the weak causal analysis frameworks. We describe two of the more comprehensive, observational studies in this note. Brady (2014) conducted a national study of effects of PDMPs on opioid prescriptions from 1999 to 2008 and found no statistically significant effect. However, this study did not differentiate between PDMP types and did not include state fixed effects. Reisman et al. (2009) reported results from a time-series comparison between states that had PDMPs and states that did not have PDMPs during the period between 1997 and 2003. PDMPs states experienced slower growth in oxycodone and hydrocodone sales.
} 
Care Survey from 2001 to 2010 and a difference-in-differences (pre- and post-test with comparison group) research design. This study exploited the significant increase in state PDMPs during this period. Results indicated that the implementation of a PDMP was associated with a 33\% decline in opioid prescriptions. Dowell et al. (2016) found similar results using a similar research design, slightly later period of analysis (2006 to 2013) and data from the IMS National Prescription Audit, which tracks prescriptions dispensed by pharmacies. Kaestner and Ziedan (2019) used information on prescription opioids from the Automated Reports and Consolidated Ordering System (ARCOS) of the Drug Enforcement Agency (DEA) from 2002 to 2016 and a difference-in-differences approach to examine the effect of PDMPs and pill mill laws on prescription opioids. They reported that pill mill laws reduced prescription opioids by approximately $15 \%$ to $20 \%$ and that the creation of a "modern" PDMP was associated with a $5 \%$ to $10 \%$ decrease in prescription opioids. Larger effects were found for hydrocodone and oxycodone, which are the two most prevalent opioids.

A study particularly relevant to our research is by Wen et al. (2017) because it focused on Medicaid enrollees. Medicaid enrollees make up a large share of women giving birth. Thus, it is particularly important that these authors found that mandatory use of a PDMP was associated with a $10 \%$ decrease in opioid prescriptions.

Other studies provide additional evidence that PDMPs reduced prescription opioids. Rutkow et al. (2015) conducted a case study of the implementation of a PDMP in Florida in 2011. The authors examined pre-to-post PDMP changes in the prescribing behavior and opioid use of a closed panel (i.e., no compositional change) of physicians, pharmacies and patients. The authors used Georgia as a comparison. Results from the study indicated that Florida's PDMP decreased opioid prescriptions by between 2\% and 6\% within 12 months. Two studies of PDMPs used Medicare data and samples of elderly: Moyo et al. (2017) and Buchmueller and Carey (2017). These studies used a difference-in-differences research design and data between 2007 and 2012-13. Buchmueller and Carey reported that must-access PDMPs were associated with modest (2\% to $3 \%$ ) reductions in prescription opioid use. Moyo et al. (2017) reported mixed evidence, but found that the total quantity (in weight) of opioid prescription declined by 
approximately $5 \%$, but that other measures of prescription opioid use did not decrease. An important finding in Buchmueller and Carey (2017) is that it is mainly the required use mandate of a PDMP that causes the decline in opioid use. ${ }^{5}$

To summarize, there is substantial evidence that PDMPs and pill mill laws reduced prescription opioid use across a variety of demographic groups including those covered by Medicaid. Therefore, it is plausible that these polices have influenced infant health as described earlier, either by reducing mis-use and abuse of prescription opioids, which would have beneficial effects, and/or by reducing medical use of prescription opioids, which may have adverse effects.

\section{Data}

We conduct four analyses: an analysis of the effect of prescription opioid policies on prescription opioid use (i.e., first stage); an analysis of the effects of prescription opioid use on infant health and maternal behaviors (OLS); an instrumental variables analysis of the effect of prescription opioid use on infant health and maternal behaviors; and an analysis of the effect of prescription opioid policies on infant health and maternal behavior (i.e., reduced form). We use data from several sources to conduct these analyses.

\section{3.a. Birth Records}

We obtain information on infant health from the universe of birth certificates collected as part of the National Vital Statistics System of the National Center for Health Statistics. We use data on infants born between 2003 and 2017. This yields a sample of approximately 64 million births. These data include measures of infant health, such as birth weight, and maternal health during the gestational period, such as weight gain during pregnancy, number and initiation timing of prenatal visits, and smoking.

We use several measures of infant health in our analyses. We examine birth weight in grams and whether the birth weight was below 2500 grams. Birth weight is often used as a summary measure of

\footnotetext{
${ }^{5}$ Patrick et al. (2016), Birk and Waddell (2017) and Grecu et al. (2019) also emphasize the importance of focusing on specific aspects of PDMPs. All three of these studies reported that PDMPs are associated with fewer serious opioid-related incidents such as treatment admissions and mortality.
} 
infant health, and low birth weight (LBW) in particular is associated with a range of poor outcomes (Black et al., 2007; Almond et al., 2018). We also examine gestational age, which is measured in weeks. For data prior to 2015, gestational age is based on information on the last month of normal menses. In 2015 onward, gestational age is based on the obstetric estimate of gestation at delivery. Both measures of gestational age are highly correlated (Martin et al. 2015). Another measure we use is the probability of having a $\mathrm{C}$-section. We examine $\mathrm{C}$-sections because prescription opioid (mis) use may affect pregnancy complications.

Note that we do not analyze the effect of state policies and prescription opioid use on neonatal abstinence syndrome (NAS). While NAS is a salient outcome it remains quite rare even in the later stages of the opioid epidemic -7 per 1000 births in 2016 according to the CDC. Therefore, the ability to reliably detect an effect of state policies and prescription opioid use on this outcome is difficult from a statistical point of view. Exacerbating the statistical problem is that measurement of NAS is problematic, as diagnosis and reporting is not systematic (San Lorenzo et al. 2018; Wachman et al. 2018). A particularly worrisome issue in this regard is the potential that reporting of NAS is correlated with the rise in opioid use. As the opioid epidemic grew and became more salient, the diagnosis of NAS may have grown accordingly. Third, information on NAS is not readily available and needs to be constructed from hospital discharge records, which are not available for many states and that are potentially subject to the reporting inconsistencies noted above (Ko et al. 2016; Jilani et al. 2019). Finally, the outcomes we examine, and which are well measured, such as low-birth weight and preterm birth, capture aspects of NAS, which is associated with relatively high rates of low-birth weight and preterm birth (Linsokova et al. 2019).

In addition to infant health measures, we also analyze maternal behaviors that may depend on prescription opioid use. We examine weight gain during pregnancy, smoking and prenatal visits. Measures of prenatal visits include the number of prenatal visits throughout the pregnancy; whether the first visit was in first trimester; and an indicator for inadequate prenatal care (Kotelchuck 1994). We use information in the births record that identifies whether a mother smoked during pregnancy to measure 
tobacco use. Information on smoking recorded on birth certificates is thought to provide a reasonably reliable source of data on prenatal smoking (Nielsen et al. 2014; Wehby et al. 2016), although underreporting of smoking status has been suggested for as much as $20 \%$ of all smokers (Tong et al., 2013). Still, this underreporting is unlikely systematically correlated with the state's opioid policies.

Weight gain is measured by an indicator that mother gained less than $20 \mathrm{lbs}$.

We also use the information on demographic characteristics from the birth certificates, such as mother's age, educational attainment, marital status, live-birth order, race, and geographic area. We aggregate the data to the month of birth-state-demographic group level. We do this to reduce the computational burden of the analysis. Specifically, we create demographic groups using 27 age groups (18 to 44), six education groups (less than high school, high school, some college, college or more, missing, not-reported), two marital status groups (married and unmarried) and four race and ethnicity groups (non-Hispanic white, non-Hispanic black, Hispanic and other). There are 1296 possible groups within each state and month (of conception). So, for each year and state there are a maximum of 15,552 observations $\left(1296^{*} 12\right)$, but there are usually much fewer because there are no births in many of the 1296 possible groups.

In some analyses, we conduct separate analyses for four samples divided according to age and marital status. We use two age groups (ages 18 to 25 and 26 to 44) and two marital status groups (married and not married) to create the four groups. This stratification is motivated by differences in prescription opioid use and mis-use, which we describe more fully below. We note that we do not use maternal education to stratify the sample because education is poorly measured on birth certificates from 2011 to 2014. In these years mother's education was not reported if the state had not adopted the revised (2003) birth certificate

\section{3.b. Prescription Opioid Information}

Ideally, we would have information on prescription opioids that includes the days supplied and dosage, as these indicators are related to medical use and mis-use of prescription opioids, and are conceptually related to the potential effects of prescription opioids on infant health. However, such data is 
not readily available. To measure prescription opioid use, we use the Drug Enforcement Agency's Automation of Reports and Consolidated Orders System (ARCOS). ARCOS data are publicly available and we used data from 2002 to $2017 .^{6}$

ARCOS reports total grams of retail prescription opioids sales per quarter per drug (i.e., active ingredient) at the state level. We use the top 14 most frequently retailed opioids (Codeine, Dihydrocodeine, Hydrocodone, Hydromorphone, levorphanol, Meperidine pethidine, Morphine, Oxycodone, Oxymorphone, Opium Powdered, Alfentanil, Remifentanil, Sufentanil base, Tapentadol). ${ }^{7}$ Notably, we exclude Fentanyl, Methadone and Buprenorphine because Methadone and Buprenorphine are prescribed for the management of opioid-dependent individuals, and are therefore fundamentally different clinically than the other prescription opioids. We exclude Fentanyl because it is sold primarily in patch and pill form. The Fentanyl patch is more potent than the pill and has a different absorption mechanism. We are unable to distinguish the type of Fentanyl in the ARCOS data and to convert it to a common dosage unit.

To characterize the quantity of prescription opioid use during the preconception and pregnancy periods, we average prescription opioid sales over the 18 months prior to birth. We use an 18 -month period because prescription opioid use during the preconception period, as well as during pregnancy, may affect pregnancy and infant health, for example, by leading to addiction or relief from pain. ARCOS data are reported quarterly and we know the month of each birth. Therefore, we use this information to construct the prescription opioid use per month and the average of that per-month use in the 18-months period prior to birth. Prescription opioid sales are converted into morphine equivalents grams (MEG) to allow for aggregating across specific drugs. We use the quarterly totals reported in AROCS and assume that prescription opioid sales are evenly divided in the three-month period that make up a quarter. With these data, we then calculate the opioid sales per month and then average over the 18 -month period prior

\footnotetext{
${ }^{6}$ We did not use earlier years because of potential reporting problems. For example, in 2000 only two opioids were reported in ARCOS - Hydrocodone and Oxycodone - and in 2001 California had a huge discrepancy in the total opioid grams reported in 2000 vis-à-vis 2001.

${ }^{7}$ The 14 opioids we selected represent over $99 \%$ of all opioids other than Fentanyl, Methadone and Buprenorphine.
} 
to birth. For example, for a birth that occurs in December of 2010, we use the average prescription opioid use between July 2009 and December 2010. We use two measures of opioid sales: the natural logarithm of the total MEG per month and the MEG per 100 persons per month.

There are some limitations of ARCOS to note. The data over-represent the amounts of prescription opioids that are distributed for human consumption because they include prescriptions used for veterinary purposes. Additionally, these data may over-represent amounts dispensed or consumed by patients because they include amounts re-ordered to replace drugs stolen from pharmacies or other retail-level dispensers, and amounts distributed to the retail level that were not actually dispensed or consumed by patients in the same year. Finally, ARCOS does not report prescription opioids by any demographic group, which is a point we discuss below.

\section{3. c. PDMPs and Pill Mill Laws}

Prescription Drug Monitoring Programs (PDMPs) are widely seen as one of the most effective policies to deter opioid mis-use and abuse and are now present in all states. In this research, we exploit the substantial growth in PDMPs in recent years. Between 2000 and 2010, 25 PDMPs were established. In addition to this growth the establishment of PDMPs, there has been significant efforts by states to make PDMPs more effective, for example, making them fully electronic with easy access to physicians and pharmacists and mandating use. ${ }^{8}$

We rely on prior evidence to construct measures of PDMPs. We draw heavily from the information in Horwitz et al. (2018) to identify the timing of implementation and to classify in a parsimonious way the main elements of PDMPs. We use dates for the enactment of a PDMP, establishment of an electronic PDMP, and establishment of a modern accessible PDMP from Table 2 of Horwitz et al. (2018). These authors carefully compared data sources on PDMP dates and offer a transparent outline for how they settled on those dates. We define three categories of PDMPs: the

\footnotetext{
${ }^{8}$ There are other state policies that we do not to include in our analysis (e.g., ID laws and quantity limits). To the extent PDMPs and "pill mill" laws are coincident with these other policies, then estimates of the effect of PDMPs and "pill mill" laws will include the effect of these programs.
} 
adoption of an electronic PDMP, the adoption of a "modern" PDM without distinguishing between whether there was a use mandate, and a residual category that includes no PDMP and a PDMP that was enacted, but not electronic. We construct mutually exclusive categories for PDMPs. These categories reflect the following attributes. An electronic system is not paper-based and allows the prescriber to transmit the prescription information electronically to the state authority (Manchikanti, Brown and Singh 2002). A “modern" PDMP is when the PDMP becomes accessible to any authorized user (e.g., physician, pharmacist, or member of law enforcement). While some past research has focused on mandates to query the PDMP, Kaestner and Ziedan (2019) found that there was no additional impact of a use mandate on prescription opioid use once controlling for the fact that the PDMP was modern.

The other policy we focus on are pill mill laws. Pill Mill laws target prescribers (pain management clinics) who account for a disproportionate share of opioid prescribing. Pill Mill laws include legal provisions establishing state inspection authority, restricting cash payments, or requiring specific training requirements for Pill Mill owners or associated physicians. ${ }^{9}$ These laws are associated with a decrease in the number of pain management clinics (Gau et al 2017). In choosing the dates that best reflect when Pill Mill laws were activated, we followed Buchmueller and Carey (2018), Malllatt (2017) and Rutkow et al. (2017). Buchmueller and Carey (2018) recorded 7 states with pill mill laws (FL, KY, MS, OH, TN, TX, WV), Malllatt (2017) recorded 8 states with pill mill laws (adding LA's pill mill law in 2005) and Rutkow et al. (2017) recorded 11 states with pill mill laws (adding WI in 2016, GA in 2013, and AL in 2013). Since WI's pill mill law is enacted in the end of 2016 we do not include WI as treated in our sample period (2002-2016). We also do not include GA because unlike other state pill mill laws, GA's does not abolish the use of cash transactions nor does it allow for random inspections of pain management clinics.

Figure 1 shows changes over time in state PDMPs using a classification of PDMPs that we have adopted. As Figure 1 shows, there is variation over time within states in both the extensive margin,

\footnotetext{
${ }^{9}$ https://www.cdc.gov/phlp/docs/menu-pmcr.pdf contains a description of the scope of various Pill Mill laws across states.
} 
reflected in the creation of electronic PDMPs, and at the intensive margin, reflected in significant changes in the structure of PDMPs as reflected in the growth of what we refer to as "modern" PDMPs.

Using the month and year of birth, we characterize exposure to the state opioid policies as the proportion of the period 18 months prior to birth that a policy was in place. As noted, we us an 18-month period because of the potential for prescription opioid use to affect preconception, and thus, pregnancy health.

\section{Empirical Approach}

\section{4.a. Effects of Prescription Opioids on Infant Health}

The primary objective of our research is to obtain estimates of the effect of prescription opioids on infant health and maternal behaviors. As noted above, the data for this analysis is derived from birth certificates and ARCOS. The data are aggregated to the month of birth and demographic group level. The basic regression model to obtain estimates is:

(1) INFANT_HEALTH $_{i j t}=\gamma_{j}+\delta_{t}+\beta O P I O I D S_{-}$PREGNANT $_{j t}+\lambda D E M O G_{i t}+v_{i j t}$ Equation (1) denotes that the average of the measure of infant health (INFANT_HEALTH) of births of demographic group " $i$ ” in state “ $j$ ” in year " $t$ ” depends on state fixed effects $\left(\gamma_{j}\right)$, year fixed effects $\left(\delta_{t}\right)$, prescription opioid use among women of reproductive age and pregnant women in state " $\mathrm{j}$ " at year " $\mathrm{t}$ " (OPIOIDS_PREGNANT) and dummy variable indicators of demographic variables (e.g., race, age, education and marital status of the mother). We also include month of birth indicators because the data are at the month level (to define prescription opioid use more precisely). We use a several measures of infant health, as described earlier, as well as previously described measures of maternal health behaviors as dependent variables. Estimates of equation (1) are obtained using weighted least squares because of the use of data aggregated data; the weight is the number of observations in the month-year cell. Standard errors of estimates are constructed using robust-cluster methods allowing for non-independence of observations within a state. 
There are a few points to note about the analysis based on equation (1). First, because prescription opioid use may have effects on infant health through its effect on a mother's preconception health, as well as pregnancy health, we measure prescription opioid use as an average of prescription opioid use in the 18-months prior to birth. Second, the ARCOS measure of prescription opioids is not specific to pregnant women or women of reproductive age, which is the measure of opioid use we would ideally include in the analysis. Therefore, there is some measurement error in the measure of exposure. Consider the following possibility:

$$
\text { OPIOIDS }_{-} \text {PREGNANT }_{j t}=\rho O P I O I D S_{j t}+u_{j t}
$$

Equation (2) indicates that prescription opioid use among women of reproductive age (pregnant women) is a constant share $(\rho)$ of total opioid sales $(O P I O I D S)$ in a state and year. Substituting equation (2) into equation (1) yields:

(3) INFANT_HEALTH $_{i j t}=\gamma_{j}+\delta_{t}+\beta \rho O P I O I D S_{j t}+\lambda D E M O G_{i t}+e_{i j t}$

The regression of infant health on total prescription opioids produces an estimate of the effect of prescription opioid use by women of reproductive age and pregnant women on infant health that is smaller (attenuated) than the true estimate $(\beta>\beta \rho, 0<\rho<1) \cdot{ }^{10}$ Estimates from equation (3) that use the per-100 persons measure of opioid use will need to be interpreted accounting for attenuation, for example, by multiplying by $(1 / \rho)$. If we measure opioid sales in natural logarithm units, however, then we will not have to be concerned with the attenuation because the change in $\ln \left(\rho O P I O I D S_{j t}\right)$ is equal to the change in $\ln \left(\right.$ OPIOIDS $\left._{j t}\right)$.

A third issue to note about equation (3) is that opioid sales are at the state and year level and are an aggregate while infant health is measured at individual level. Ideally, we would measure opioid use by

\footnotetext{
${ }^{10}$ More generally, if the relationship between opioid use by pregnant women and total opioid use varies by state and/or year then estimates of the effect of prescription opioid use by pregnant women on infant health will still be smaller than the true estimate, but there will also be heterogeneous effects by state and year. If there is this type of heterogeneity, then we are estimating the average of those heterogeneous effects. Note that this type of heterogeneity should not be confused with that described in Goodman-Bacon (2019) and others.
} 
an infant's mother. Only a fraction, for example $15 \%$ to $25 \%$, of women of reproductive age and pregnant women (mis) use prescription opioids and are at risk of exposure. Thus, we are not measuring the effect of individual, maternal opioid use on infant health, but on opioid use of the population. This is an interesting parameter because it measures the effect of prescription opioid use and prescription opioid control policies at the population health level, which is of interest to policy. However, to recover the estimate of the effect of maternal (individual) use of opioids on infant health it is necessary to scale the estimates we obtain by one divided by the proportion of the population likely affected, which based on evidence is approximately $15 \%$ to $25 \%$. We acknowledge that scaling estimates in this way is only a rough approximation of the effect of interest.

Next, we conduct analyses that allows for the possibility that prescription opioid use is endogenous. There may be unmeasured variables associated with both prescription opioid use and infant health outcomes that would bias estimates of equation (3). For example, changing economic factors may affect both prescription opioid use among women of reproductive age and pregnant women and infant health. To address this issue, we estimate regression models that sequentially add additional variables in a cumulative manner:

- the unemployment rate in state " $\mathrm{j}$ " and year " $\mathrm{t}$ " in the 18 months prior to birth; share of people in state $\mathrm{j}$ and year $\mathrm{t}$ in poverty and the Medicaid income eligibility threshold for pregnant women in state " $\mathrm{j}$ " and year " $t$ ";

- interactions between these state characteristics and year (see Jaeger et al. 2020);

- and finally, linear state-specific time trends.

The purpose of these additional specifications is to control for confounding from omitted, state-specific time-varying factors. We refer to these specifications as models 1, 2 and 3 and will use these designations throughout the rest of the article.

A second way we address the potential endogeneity of prescription opioid use is through the use of an instrumental variables (IV) approach. The IV approach uses plausibly exogenous variation in prescription opioid sales that is caused by states' adoption of prescription opioid control policies. To 
implement the approach, we estimate a model that predicts prescription opioid sales using variation in the timing of state adoption of PDMPs and pill mill laws (i.e., first stage). This is a difference-in-differences model shown by the regression below:

$$
\begin{aligned}
& \text { (4a) } \rho O P I O I D S_{j t}=\tilde{\gamma}_{j}+\tilde{\delta}_{t}+\sum_{k=1}^{3} \pi_{k} P D M P_{k j t}+\tilde{\lambda} D E M O G_{i t}+\tilde{v}_{j t} \\
& \text { (4b) } \text { OPIOIDS }_{j t}=\tilde{\gamma}_{j}+\tilde{\delta}_{t}+\sum_{k=1}^{3}\left(\pi_{k} / \rho\right) P D M P_{k j t}+\tilde{\lambda} D E M O G_{i t}+\tilde{v}_{j t}
\end{aligned}
$$

Equation (4a) indicates that prescription opioid use of women of reproductive age and pregnant women in state "j" and year "t" ( $\left.\rho O P I O I D S_{j t}\right)$ depends on state fixed effects $\left(\tilde{\gamma}_{j}\right)$, year fixed effects $\left(\tilde{\delta}_{t}\right)$, three state policies (electronic PDMP, modern PDMP and pill mill law), and demographic characteristics (DEMOG). Note that the subscript for time is not quite accurate because opioids are measured at the month level and represent the average monthly sales in the 18 months prior to birth. As in equation (1), we include month of birth fixed effects. We also measure the policy variables as the proportion of time that the policy was in effect in the 18-month period prior to birth. We use the predicted value from the first stage regression as an instrumental variable for actual prescription opioid use in equation (3).

Equation (4b) assumes that the effect of state prescription opioid policies on prescription opioid use $\left(\pi_{k}\right)$ is the same for all demographic groups, including women of reproductive age. If that is not a correct assumption, then estimates of the effect of state prescription opioid policies on prescription opioid from equation (4b) would differ from the true effect of these policies on the prescription opioid use of women of reproductive age, as shown next:

$$
\begin{aligned}
& \text { (4a) } \rho O P I O I D S_{j t}=\tilde{\gamma}_{j}+\tilde{\delta}_{t}+\sum_{k=1}^{3} \pi_{k} P D M P_{k j t}+\tilde{\lambda} D E M O G_{i t}+\tilde{v}_{j t} \\
& (4 b) \operatorname{OPIOIDS}_{j t}=\tilde{\gamma}_{j}+\tilde{\delta}_{t}+\sum_{k=1}^{3}\left(\tilde{\pi}_{k} / \rho\right) P D M P_{k j t}+\tilde{\lambda} D E M O G_{i t}+\tilde{v}_{j t} \\
& \tilde{\pi}_{k} \neq \pi_{k}
\end{aligned}
$$

If we substitute the new, equation (4b) into equation (3):

(5) $I N F A N T_{-} H E A L T H_{i j t}=\gamma_{j}+\delta_{t}+\left[\sum_{k=1}^{3}\left(\beta \tilde{\pi}_{k}\right) P D M P_{k j t}\right]+\lambda D E M O G_{i t}+e_{i j t}$ 
Equation (5), which is the IV estimate expressed in terms of reduced form coefficients, shows that IV estimates would be biased if the effect of state prescription opioid policies on prescription use of women of reproductive age differed from the average effect $\left(\tilde{\pi}_{k} \neq \pi_{k}\right)$. We discuss this issue in the next section when we describe the reduced form analysis.

There are two primary issues related to the validity of the IV approach. The first is whether the state policies we use as instruments actually predicts prescription opioid use. We have demonstrated that this is the case in Kaestner and Ziedan (2019), but we do so again in this article to confirm this result using the sample of births. We note here that the first stage estimates in Kaestner and Ziedan (2019) are from a regression of opioid quantities on state opioid policies, where we define exposure to be the proportion of the previous 12 months that the policy was in effect. There, we do this for each quarterly observation of prescription opioid sales and then we aggregate the quarterly data to the year level. In this article, we define exposure to be the proportion of the 18-months prior to births that a policy was in effect (9-months pre-conception and 9-months of gestation). The different exposure windows do not generate qualitatively different results, but are noted here to highlight that estimates in Kaestner and Ziedan (2019) and the estimates reported here differ in magnitude slightly.

The second assumption is whether the exclusion restriction holds - that the instruments can be omitted from equation (3). This assumption implies that the only effect of PDMPs and pill mill laws on infant health operates through prescription opioid use. We see no obvious reason why this assumption would not hold, particularly given evidence in Kaestner and Ziedan (2019) who showed that the parallel trend assumption underlying the validity of the first stage regression seems to hold. While not the same as the exclusion restriction, this prior evidence shows that trends in prescription opioid sales in states that did and did not adopt opioid control policies were similar. In addition, Kaestner and Ziedan (2019) showed similar results for employment and other socioeconomic outcomes when estimating the reduced form relationship between opioid control policies and these outcomes. Here, we add to this evidence and assess the likely validity of this assumption by conducting tests of overidentification. This test can be 
done because we have three instruments for prescription opioid use. We note that we cannot reject the validity of the exclusion restriction.

\section{4.b. Effects of State Prescription Opioid Control Policies on Infant Health}

An alternative approach that provides evidence of the effects of prescription opioid use on infant health and maternal behaviors is to use the reduced form model. The reduced form model is a regression of infant health (maternal behavior) on the state prescription opioid control policies. The intuition of the reduced form model is that the state policies will alter prescription opioid use and, in turn, (possibly) affect infant health. The combined effect of these pathways is measured by the reduced form coefficients of the state policies.

The reduced form has a potential advantage relative to the instrumental variables approach because of the limited nature of the ARCOS information on prescription opioids. As noted, the ARCOS data has total grams of prescription opioids measured at the state and quarter level. ARCOS does not provide data at the demographic level or by the type of prescription (e.g., days supplied). The reduced form, however, will reflect the effect of the state policies on prescription opioid use of women of reproductive age and pregnant women, and in models stratified by age and marital status, women in these groups.

The reduced form model is:

(6) INFANT_HEALTH $H_{i j t}=\gamma_{j}+\delta_{t}+\left[\sum_{k=1}^{3}\left(\beta \pi_{k}\right) P D M P_{k j t}\right]+\lambda D E M O G_{i t}+e_{i j t}$

Note that in equation (6) the reduced form coefficients $\left(\beta \pi_{k}\right)$ reflect the true effect of state opioid policies on prescription use of women of reproductive age and pregnant women $\left(\pi_{k}\right)$ whereas the IV estimate (as shown in equation 5) does not necessarily do so. We can assess the extent of the potential bias of the IV estimate, however, by comparing IV estimates obtained using equation (4b) and reduced form estimates of equation (6):

(7) $\beta=\beta \tilde{\pi}_{k} / \pi_{k}$ 
Equation (7) is the well-known relationship between the IV estimate ( $\beta$ ) and the scaled reduced form estimate $\left(\beta \tilde{\pi}_{k} / \pi_{k}\right)$. If the IV estimates and the scaled reduced form estimates align—are close in value - then this is evidence that the assumption that state prescription opioid policies affect the prescription opioid use of women of reproductive age similarly to how these policies affect overall use. We report evidence on this below, but note here that the IV and scaled reduced form estimates are quite similar. This evidence supports the claim that the IV estimate is valid and measures the effect of changes in prescription opioid use among women of reproductive age and pregnant women on infant health and maternal behaviors.

The validity of the reduced form depends on the assumption that trends over time in infant health and maternal behaviors would be the same for states changing opioid control policies and states not changing such policies. Kaestner and Ziedan (2019) found this to be the case for socioeconomic outcomes and mortality, and this supports the application here. To further assess the validity of the difference-indifferences design of the reduced form, we proceed as above and estimate regression models that sequentially add variables potentially related to missing and confounding influences (i.e., models 1, 2 and 3). The assessment of the validity of the approach is whether adding the additional controls has a marked effect on estimates.

\section{4.c. Analyses Stratified by Demographic Characteristics}

We conduct analyses using samples stratified by age and marital status. The justification for stratifying the sample by these characteristics is that they are associated with use and mis-use of prescription opioids. Our hypothesis is that state policies that restrict prescription opioid use are more likely to have beneficial effects among groups that are more likely to mis-use/abuse prescription opioids. Stratifying the data by age and marital status helps identify these groups. Table 1 shows differences in prescription opioid (pain reliever) use and mis-use (non-medical use) by age and marital status for women in the beginning of our period of analysis. As can be observed, prescription opioid mis-use is particularly high among younger women and younger, unmarried women in particular. Among the latter group, 11\% 
of young unmarried women have reported non-medical use of prescription opioids in past year and 19\% report any illicit drug use other than marijuana in past year. In contrast, older, married women report little non-medical use of prescription opioids (3\%) and illicit drugs other than marijuana (5\%). And as previous research has documented, women covered by Medicaid have relatively high rates of use and mis-use of prescription opioids. Marital status and age are also highly correlated with probability of being on Medicaid among women giving birth. For example, $74 \%$ of the births of unmarried, pregnant women age 18 to 25 were covered by Medicaid.

\section{Results for Full Sample}

\section{5.a. First Stage: Effects of PDMPs and Pill Mill Laws on Prescription Opioid Sales}

We begin the discussion with the first stage estimates of the effects of PDMPs and pill mill laws on prescription opioid sales. We adopt this order of presentation because the instrumental variables and reduced form analyses are premised on the fact that these opioid control policies change prescription opioid use. If true, then adoption of these opioid control policies generates plausibly exogenous variation in prescription opioid use that we can use to measure the effect of prescription opioid use on infant health and maternal behaviors.

Table 2 presents the estimates of the effect of opioid control policies on prescription opioid sales. The table shows sets of estimates for four dependent variables that differ by whether we are measuring all prescription opioid sales or just the top two prescription opioids (hydrocodone and oxycodone) and whether they are measured as log MEG grams or per-capita MEG grams. We separate hydrocodone and oxycodone because these prescription drugs are the main opioids prescribed for pregnant women. We measure prescription opioid sales in two ways to assess whether the functional form of the dependent variable matters. Specifically, we use the natural logarithm $(\log )$ of the average monthly prescription opioid sales in the 18-month period prior to pregnancy measured in MEG and the average monthly MEG per 100 persons in the 18-month period prior to pregnancy. For each of the four dependent variables, we 
estimate models using the three specifications noted above that control for a different set of variables (i.e., models 1,2 and 3). Regressions are weighted by the number of births in a cell. ${ }^{11}$

While there are many estimates presented in Table 2, there is a clear pattern to the estimates that lead to a couple of conclusions. First, all estimates associated with the adoption of a modern PDMP and pill mill law are negative and most are statistically significant. Second estimates associated with pill mill laws are large. Third, estimates related to hydrocodone and oxycodone are larger than those for all prescription opioids. Finally, estimates associated with adoption of an electronic PDMP are small and mostly non-significant.

As noted, the magnitudes of the estimates associated with pill mill laws are large. For example, estimates from model 2 suggest that adoption of a pill mill law is associated with a $21 \%(0.214 \mathrm{ln}$ points $)$ and 37\% ( 0.368 ln points) decrease in sales of al opioids and hydrocodone and oxycodone, respectively. Analogous estimates for the adoption of a modern PDMP indicate that this policy is associated with an $11 \%(0.113$ and 0.115$)$ decrease in all opioid sales and hydrocodone and oxycodone sales.

Estimates from models that use opioid sales per 100 persons are similar. The estimate in model 2 indicates that adoption of a pill mill law is associated with a 1.4 grams $(36 \%)$ decrease in all opioid sales and it is significant at 0.01 level. But for this measure of opioid sales, we will need to multiply by ( $\rho$ ) to make it comparable to estimates from the model that use the natural logarithm of opioid sales. We assume that the share of all opioid sales that pertain to women of reproductive age (i.e., $\rho$ ) is equal to the share of women of reproductive age's in the adult population, which is $25 \%$. Multiplying the 1.4 grams estimate by 0.25 yields an adjusted estimate of $0.35(9 \%)$. While somewhat smaller than the estimate from the model using $\log (\ln )$ opioid sales, we note that this approximation is somewhat crude and is used to make the point that whether we use $\log (\ln )$ opioid sales or a per-100 persons measure, estimates are qualitatively similar (and equally statistically significant).

\footnotetext{
${ }^{11}$ Results are very similar to those reported in Kaestner and Ziedan (2019) that weight the regressions by population.
} 
A final comment about estimates in Table 2 is that while there is some sensitivity of estimates to model specification, estimates are qualitatively and often quantitatively similar across specifications, particularly if we consider confidence intervals. Of note, however, is that the standard errors of estimates associated with pill mill law from models that include state-specific trends are approximately double the size of standard errors from other models. This is likely due to the fact that most states adopted pill mill laws around 2011 (see Figure 1) and that there are only eight such states. Given that the pill mill estimates are large and change prescription opioid sales substantially more than adoption of a modern PDMP, the large standard errors reduce the strength of the first stage correlation between the opioid policies and prescription opioid sales. This lack of precision will reduce the efficacy of IV and reduced form estimates. Therefore, we do not present reduced form and IV estimates from models that include state-specific trends (model 3). The similarity of the estimates across model specification bolsters the case for a causal interpretation and is consistent with the more extensive evidence in Kaestner and Ziedan (2019) that assessed the validity of the difference-in-differences research design underlying estimates in Table 2 . In Figures 2 and 3, we present event-study estimates of the effect of modern PDMP and pill mill law on prescription opioid sales using model 2 (includes interactions between baseline variables and year). These figures show that, generally, there were no differential trends in prescription opioid sales prior to implementation of these policies in states with and without these policies. They also show visual evidence that is highly consistent with the estimates in Table 2 .

\section{5.b. OLS and IV Estimates of the Effect of Prescription Opioid Sales on Infant Health}

We next turn to the analysis of the effect of prescription opioid sales on infant health. As noted earlier, we use aggregate prescription opioid sales as an indicator of prescription opioid use among women of reproductive age and pregnant women. We use measures of all opioids and for only hydrocodone and oxycodone. We examine the effect of prescription opioid sales on four outcomes: birthweight in grams; an indicator of low birthweight ( $<2500$ grams); gestational age measured in weeks; and an indicator for whether delivery was by c-section. For each dependent variable, we present OLS and 
IV estimates using three model specifications that include a larger set of control variables and described earlier.

Table 3 reports OLS and IV estimates for models that use log MEG of prescription opioids and Appendix Table 1 presents analogous estimates for models that use opioids per-100 persons. Estimates related to all opioids are in the top panel and estimates for hydrocodone and oxycodone in the bottom panel. We begin the discussion with respect to birthweight. All OLS estimates of the effect of prescription opioid sales on birthweight are insignificant and small in magnitude. For example, estimates from what we refer to as model 2 indicate that a 100\% increase in opioid sales (i.e., a one log point increase), either all opioids or just hydrocodone and oxycodone, is associated with approximately a one to two grams change in birthweight. IV estimates in Table 3 indicate that an increase in prescription opioid sales is associated with a significant decrease in birthweight. Estimates from model 2 suggest that a $100 \%$ increase in all prescription opioids is associated with a 22 grams decrease in birthweight. The analogous estimate for hydrocodone and oxycodone is 12 grams.

To put these IV estimates in context, note that a $100 \%$ increase in opioid sales is the change that occurred between 2002 and 2010, and is, therefore, within the variation observed in the data. Also, because we are using the natural logarithm of opioid sales, we do not have to adjust for the attenuation bias that stems from the fact that we are using aggregate opioid sales and not opioid sales (or use) among women of reproductive age. ${ }^{12}$ However, it is still the case that only a fraction, for example, $15 \%$ to $25 \%$ of women used prescription opioids (see Table 1 and evidence cited in Introduction). Thus, the 12 to 22 grams reduction in birthweight for the population is due to a change in opioid use by approximately $20 \%$ of women. If so, then inflating by a factor of $5(\approx 1 / 0.2)$ would yield effect sizes of 60 and 100 grams. Effects sizes of this magnitude are consistent with clinical evidence on the effects of serious opioid use

\footnotetext{
${ }^{12}$ For the per-100 persons estimates in Appendix 1, we do need to make this adjustment. We would multiply estimates by a factor of $4(1 / \rho=1 / 0.25=4)$. Doing so for estimates from model 2 yields estimates of the effect of a 4 unit change in opioids per 100 persons, which is about a $100 \%$ change and comparable to a one log (ln) point change, of approximately 40 grams. The comparable estimate in table 3 is 22 grams. Again, we caution that these adjustments are approximate and are used to illustrate the similarity of estimates.
} 
such as heroin (Hulse et al. 1997). We acknowledge, however, that inflating estimates this way is a crude approach. We report these calculations simply to provide a ball-park estimate of interest - the effect of actual prescription opioid use on birthweight. To provide additional context about the magnitudes of these estimates, we note that prior research has shown that smoking during pregnancy is associated with between 150 grams and 300 grams decrease in birthweight (Murin et al. 2011). The upshot is that estimates suggest that reductions in prescription opioid use as a result of state opioid control policies may have substantial benefits for population health of infants and individual health of infants of mothers who use prescription opioids.

IV estimates from model 1 are similar to those just described and estimates in Appendix Table 1 (per-100 persons opioids) are also consistent with those reported in Table $3 .{ }^{13}$ The similarity of estimates across specifications is evidence supportive of the validity of the research design. In addition, we conducted an over identification test by re-estimating the IV model excluding only the pill mill law from the second stage model (i.e., just identified model). Estimates of the effects of the included instruments, electronic and modern PDMPs, were not significantly significant either individually or jointly and pvalues were quite high.

The next estimates we discuss are for low birthweight (LBW). All OLS estimates are small and not statistically significant. IV estimates are always positive and in all but one case marginally significant (p-value less 0.20 ). Focusing on model 2, IV estimates suggest that a $100 \%$ increase in all opioids is associated with a 0.3 percentage point increase in LBW. The analogous estimate for hydrocodone and oxycodone is 0.2 percentage points. ${ }^{14}$ The positive effects of prescription opioids on LBW are consistent with the negative effects of prescription opioids on birthweight. We note again, that these estimates are relevant for the population of pregnant women. To obtain estimates applicable to women who are at risk

\footnotetext{
${ }^{13}$ Estimates from model 2 in Appendix Table 1 are around -2.7 grams. These need to be adjusted for the attenuation bias discussed in the text. Assuming $(1 / \rho)$ is equal to four yields estimates of approximately -11 grams for both all opioids and hydrocodone and oxycodone. These are similar to those in Table 3.

${ }^{14}$ Estimates in Appendix Table 1 related to LBW are similar (0.002 and 0.004) once adjusting for the attenuation bias discussed above.
} 
of using prescription opioids, we would inflate these estimates by a factor of five. If we us an effect size of 0.3 percentage points and inflate it by five the implied effect of a $100 \%$ increase in prescription opioid use among women who use prescription opioids is associated with a 1.5-percentage point increase in LBW, which is large but certainly plausible. In relative terms, IV estimates of the effect of prescription opioid sales on LBW are larger than analogous estimates for birthweight. This suggests that changes in prescription opioid use primarily affects the lower tail of the birthweight distribution.

For the remaining two outcomes in Table 3 (Appendix Table 1), gestational age and c-section, both OLS and IV estimates are small and not statistically significant. Even if we inflate the estimates by a factor of five estimates remain small. The absence of an effect of prescription opioids on gestational age suggest that the effects of prescription opioids on birthweight and LBW are due to its effect on intrauterine growth.

\section{5.c. OLS and IV Estimates of the Effect of Prescription Opioid Sales on Maternal Behaviors}

Table 4 shows estimates of the effects of prescription opioids on maternal behaviors. In this table, we show only estimates from model 2 and prescription opioids are measured in log form. Appendix Table 2 contains analogous estimates when prescription opioids are measured as per-capita quantities. Estimates for all opioids are in top panel and estimates related to hydrocodone and oxycodone are in bottom panel.

With respect to the number of prenatal care visits, IV estimates are not statistically significant. IV estimates of the effect of $100 \%$ increase in all (top 2) opioid sales on number of prenatal care visits is 0.5 (0.4), which is about $5 \%$ of the mean. Iv estimates related to the timing of prenatal care and whether care was inadequate are statistically significant and suggest that greater prescription opioid use is associated with less prenatal care. IV estimates for first trimester care are $-0.125(16 \%)$ for all opioids and -0.81 $(10 \%)$ for the top two opioids. And consistent with the decrease in first trimester care, a $100 \%$ increase in all (top two) prescription opioids are associated with a $0.083(0.045)$ percentage point increase in inadequate care, which represents an effect size that is $55 \%(30 \%)$ of the mean. These IV estimates are what we refer to as population health estimates because they refer to the full population of pregnant women. Estimates that are more closely aligned with individual use of prescription opioids are obtained 
by inflating these by a factor of five. Doing so suggests that a $100 \%$ increase in prescription opioid use is associated with a one- to two-fold increase in the probability of inadequate prenatal care, which is consistent with evidence related to determinants of late prenatal care (Baer et al. 2019).

For maternal smoking, IV estimates are positive and suggest that a 100\% increase in prescription opioid sales, either all opioids or just hydrocodone and oxycodone, is associated with approximately a one (7.5\%) percentage point increase in smoking, although estimates are not statistically significant. Again, these are plausible estimates of population health effects. Even after taking account that they are attenuated estimates of the effect of individual opioid use they are plausible. There is a strong positive association between smoking and (mis) use of prescription opioids (Zale et al. 2015). So, a 100\% increase in prescription opioid use may plausibly alter smoking by a large amount, for example, five percentage points (inflating IV estimate by a factor of 5).

Overall, estimates in Table 4 (and Appendix Table 2) provide evidence that prescription opioid use is associated with an increase in inadequate prenatal care and an increase in smoking, although the latter estimates are not statistically significant. These effects of prescription opioids on prenatal care are consistent with estimates of the effects of prescription opioid use on birthweight.

\section{5.d. Reduced Form Estimates of the Effect of Prescription Opioid Control Policies on Infant Health}

The reduced form estimates of the effect of PDMPs and pill mill laws on infant health are presented in Table 5 and we present estimates only from model 2. The advantage of the reduced form approach is that estimates will reflect the relationship between state opioid control policies and prescription opioid use of women of reproductive age and pregnant women. Estimates in Table 5 related to birthweight indicate that adoption of a pill mill law is associated with approximately a 5 grams increase in birthweight and the estimate is highly significant. The effect size, while small, is consistent with the IV estimates previously reported. If we assume that pill mill laws reduce opioid use among women of reproductive age by $33 \%$ as first stage estimates suggest, then we would inflate the effect of pill mill law on birthweight by approximately a factor of three to make it comparable to the IV estimate, which would yield an effect of 15 grams. The 15 grams estimate is similar to the IV estimate of the effect of a $100 \%$ 
increase in prescription opioid sales. ${ }^{15}$ The similarity of the reduced form estimate of the effect of pill mill laws and IV estimates provides consistent evidence that pill mill laws have had an effect on infant health through lower prescription opioid use and that the lower prescription opioid use has been beneficial. The estimate of the effect of a modern PDMP on birthweight is 2.7 grams and marginally significant. The smaller effect size of this policy is consistent with the smaller first stage effect of this policy on opioid sales. ${ }^{16}$ However, if we inflate this effect by that implied by the effect of a modern PDMP on prescription opioid sales (a factor of approximately 9), again, we get something close to the IV estimates in Table 3.

Estimates of the effect of a modern PDMP and pill mill law on LBW are negative, which is consistent with the positive estimates for birthweight, but only the modern PDMP estimate is statistically significant, which is somewhat inconsistent with birthweight results. Estimates of the effect of state opioid control policies on the other outcomes in Table 5, gestational age and c-section, are small and insignificant.

In summary, the reduced form estimates are generally consistent with the IV estimates presented earlier. These results add to the evidence suggesting that state opioid control policies and reductions in prescription opioid sales have improved infant health at the population level and for individuals whose prescription opioid use has been affected. Finally, Figure 4 shows event-study estimates of the effect of a modern PDMP and pill law on birthweight. These figures provide additional evidence of the validity of the research design. There is little evidence of a violation of the parallel trend assumption underlying the difference-in-differences research design.

\section{5.e. Reduced Form Estimates of the Effect of Prescription Opioid Control Policies on Maternal Behaviors}

\footnotetext{
${ }^{15}$ And then accounting for the fact that approximately $15 \%$ of pregnant women account for that opioid use, then we would inflate the estimate by approximately seven (1/0.15) yielding an estimate of 75 grams.

16 There is not necessarily a dose-response relationship expected based on first stage results because we do not know what types of opioid use and mis-use was affected by these policies (e.g., modern PDMP and pill mill law).
} 
Table 6 shows estimates of the effects of prescription opioid control policies on maternal behaviors. Estimates of the effect of pill mill laws indicate that adoption of these laws is associated with a 3.7 percentage point increase in first trimester prenatal care and a 1.9 percentage point decrease in inadequate care. The reduced form results are consistent with the analogous IV estimates. Figures 5 and 6 show event-study estimates related to the DD estimates in Table 6. Notably, event-study estimates show no evidence of a violation of the parallel trend assumption underlying the difference-in-differences research design.

\section{Results for Samples Stratified by Age and Marital Status}

\section{6.a. OLS and IV Estimates of the Effect of Prescription Opioid Sales on Infant Health}

Prescription opioid use and mis-use differs by age and marital status, as shown in Table 1. For example, women ages 18 to 25 are more likely to mis-use prescription opioids than older women.

Therefore, the effect of state opioid control policies and resulting changes in prescription opioid use may have different effects on women stratified by age and marital status. Given this possibility, we conducted analyses stratified by these two characteristics. For these analyses, we only present results from model 2 and for log MEG opioid sales. As we will describe shortly, results for the stratified samples are very similar to those for the full sample and model 2 estimates are representative of the results. Results for unmarried women are presented in Table 7 and results for married women are presented in Table $8 .{ }^{17}$

IV estimates related to birthweight in Tables 7 and 8 are quite consistent. IV estimates of the effect of opioid sales are negative and always statistically significant. Estimates suggest that a $100 \%$ increase in prescription opioid sales is associated with between a 9 grams and 27 grams decrease in birthweight depending on the sample (age by marital status) and the types of opioids (all opioids v. hydrocodone and oxycodone). Most estimates are between 9 and 14 grams and estimates are slightly larger for married than unmarried women. These IV estimates are similar to those found for the full

\footnotetext{
${ }^{17}$ Estimates from models that use opioid sales per 100 persons are similar and not reported.
} 
sample. In general, there is not a great deal of heterogeneity in the effects of prescription opioids on birthweight across these samples.

With respect to other outcomes, there are few statistically significant estimates in Tables 7 and 8 . The only additional result to mention is that all IV estimates of the effect of prescription opioids on LBW are positive and estimates for younger, married women are statistically significant. These IV estimates suggest that a $100 \%$ increase in prescription opioid sales is associated with a 0.7 percentage point (all opioids) and 0.3 percentage point (hydrocodone and oxycodone) increase in LBW. For other samples, the analogous estimate is smaller (e.g., 0.1 to 0.2 percentage points). As with the full sample, estimates of the effect of prescription opioid sales on birthweight and LBW are consistent in that opioid sales are associated with lower birthweight and higher rates of LBW with the LBW effect being larger in relative terms.

\section{6.b. OLS and IV Estimates of the Effect of Prescription Opioid Sales on Maternal Behaviors}

Tables 9 and 10 presents estimates of the effects of prescription opioids on maternal behaviors for samples stratified by age and marital status. Here too, estimates are similar to those for the full sample. Increases in prescription opioids are associated with increases in inadequate prenatal care and estimates tend to be somewhat larger for younger women than older, which is consistent with the younger women's greater mis-use of prescription opioids. However, we do not want to push this result too far as confidence intervals clearly overlap.

\section{6.c. Reduced Form Estimates the Effect of Prescription Opioid Control Policies on Infant Health and Maternal Behaviors}

Reduced form estimates of the effect of state opioid control policies on infant health by age and marital status are listed in Tables 11 and 12. Table 11 contains results for unmarried women and Table 12 lists results for married women. Again, we only show estimates from model 2. Estimates in Tables 11 and 12 are very similar to the analogous estimates for the full sample that have been previously described and there is little need for much elaboration. Estimates reveal that adoption of a pill mill law is associated with a statistically significant 5 grams increase in birthweight. Pill mill laws also were associated with a 
0.1 percentage point decrease in LBW for younger women, but these estimates were marginally significant.

Tables 13 and 14 present reduced form estimates of the effect of prescription opioid control policies on maternal behaviors for the stratified samples. Little additional discussion is necessary as these estimates are largely similar as those for the full sample and previously described. Pill mill laws are associated with a decrease in inadequate care. This result aligns with previous findings that increases in prescription opioid sales is associated with an increase in inadequate prenatal care.

\section{Conclusions}

Prescription opioid use is relatively common among women of reproductive age and even among pregnant women. While medically prescribed prescription opioid use is generally considered safe to use during pregnancy, mis-use prior to and during pregnancy may adversely affect maternal health and, in turn, infant health. ${ }^{18}$ The substantial growth in medically prescribed prescription opioid use in the last 20 years has been accompanied by an increase in mis-use, and therefore raises the possibility that the growth in prescription opioid use has adversely affected infant health at the individual and population levels.

The concern over the opioid epidemic has brought forth policies to control mis-use of prescription opioids including inappropriate prescribing (CDC 2016). As we show, the adoption of modern PDMPs and pill mill laws has significantly reduced prescription opioid sales. The policy-driven reduction in prescription opioids is likely to improve infant health by reducing mis-use of prescription opioids by women of reproductive age and pregnant women. However, we note that the curtailment of prescription opioid use may have harmful effects if it leaves pain untreated. While there are substitutes for prescription opioids for relieving pain, these substitutes may not be equivalent. If so, then the policy-driven reduction in prescription opioids may be harmful to infant health if women of reproductive age and pregnant women are adversely affected. We examined these hypotheses in this article.

\footnotetext{
18 There is also the chance of addiction post-birth for women prescribed opioids during birth, for example, for recovery from c-section.
} 
Results from our analysis suggest that reductions in prescription opioid use that is a result of state prescription opioid policies have improved infant health modestly at the population level and more significantly at the individual level. For example, we show that the adoption of a pill mill law reduced prescription opioid sales by approximately $33 \%$. Estimates also imply that a $33 \%$ reduction in prescription opioid use is associated with a 7 grams ( $1 \%$ of a standard deviation) decrease in birthweight and a 0.1 percentage point (1\%) increase in LBW. These represent population level changes that are driven by changes in prescription opioid use among approximately $20 \%$ of women of reproductive age and pregnant women. Thus, for women at risk, state policies have had a more substantial impact on birthweight ( $\approx 35$ grams) and LBW $(\approx 0.5$ percentage points). We also find evidence that adoption of pill mill laws has improved the timely receipt of prenatal care and reduced maternal smoking (not significant) and the probability of inadequate prenatal care. The effects of prescription opioid policies and prescription opioid use on these maternal behaviors are consistent with the effects of these factors on birthweight. As these results suggest, we do not find any evidence of adverse effects of the reduction in prescription opioids on infant health. Finally, in analyses stratified by age and marital status, results were largely the same as those just described. There was not much heterogeneity, although among younger women we observed that prescription opioid use was associated with larger adverse effects on prenatal care.

Our results differ from Gihleb et al. (2020) who reported that an operational PDMP was associated with a $10 \%$ reduction in NAS, but was not significantly or clinically related to birth weight, low-birth weight and prematurity. We did not study NAS for the reasons described earlier (potential measurement problems and the rarity of NAS), but we found that a "modern" PDMP and pill mill laws were associated with small, but clinically relevant improvements in birth weight (reductions in LBW) and improvements in the timing and adequacy of prenatal care. Some of these effects may reflect changes in NAS. One explanation for the differences in results is that we used different policy measures, which we documented resulted in reduced prescription opioid sales. We also showed that the PDMP policy that 
Gihleb et al. (2020) focused on (what we refer to as electronic PDMP) was not significantly related to prescription opioid sales, nor was it significantly related to birthweight and other infant outcomes. ${ }^{19}$

In summary, our analysis has provided evidence that the substantial growth in prescription opioid use that has occurred over the last 20 years has probably adversely affected infant health at the population and individual level. We also show that the adoption of state prescription opioid policies to reduce misuse of prescription opioids has had a beneficial effect on infant health. Our results highlight the potentially diverse impacts of prescription opioid use. We note this because much of the research and policy focus on prescription opioids focuses on mortality, which while obviously important, may constitute only part of the costs and benefits of policies to control prescription opioids.

\footnotetext{
${ }^{19}$ In addition, when Gihleb et al. (2020) used slightly different sources to date the timing of the PDMP implementation that was closer to what we used, results related to NAS were no longer significant at the 0.05 level. The authors did not report similar results for other infant outcomes.
} 


\section{References:}

[1] Ailes, Elizabeth C., et al. "Opioid prescription claims among women of reproductive age-United States, 2008-2012." MMWR. Morbidity and mortality weekly report 64.2 (2015): 37.

[2] Almond, Douglas, Janet Currie, and Valentina Duque. "Childhood circumstances and adult outcomes: Act II." Journal of Economic Literature 56.4 (2018): 1360-1446.

[3] American College of Obstetricians and Gynecologists. "ACOG statement on opioid use during pregnancy." (2017).

[4] American College of Obstetricians and Gynecologists. "ACOG Committee Opinion number 313, September 2005. The importance of preconception care in the continuum of women's health care." Obstetrics and gynecology 106.3 (2005): 665.

[5] Baer, Rebecca J., et al. "Maternal factors influencing late entry into prenatal care: a stratified analysis by race or ethnicity and insurance status." The Journal of Maternal-Fetal \& Neonatal Medicine 32.20 (2019): 3336-3342.

[6] Bao, Yuhua, et al. "Prescription drug monitoring programs are associated with sustained reductions in opioid prescribing by physicians." Health Affairs 35.6 (2016): 1045-1051.

[7] Bateman, Brian T., et al. "Patterns of opioid utilization in pregnancy in a large cohort of commercial insurance beneficiaries in the United States." Anesthesiology 120.5 (2014): 1216.

[8] Black, Sandra E., Paul J. Devereux, and Kjell G. Salvanes. "From the cradle to the labor market? The effect of birth weight on adult outcomes." The Quarterly Journal of Economics122.1 (2007): 409-439.

[9] Brady, Joanne E., et al. "Prescription drug monitoring and dispensing of prescription opioids." Public Health Reports 129.2 (2014): 139-147.

[10] Buchmueller, Thomas C. and Coleen Carey. 2017. "The Effect of Prescription Drug Monitoring Programs on Opioid Utilization in Medicare” NBER working paper No. 23149 
[11] Bushnell, M. Catherine, Marta Čeko, and Lucie A. Low. "Cognitive and emotional control of pain and its disruption in chronic pain." Nature Reviews Neuroscience 14.7 (2013): 502-511.

[12] Chisolm, Margaret S., et al. "A comparison of cigarette smoking profiles in opioid-dependent pregnant patients receiving methadone or buprenorphine." nicotine \& tobacco research 15.7 (2013): $1297-1304$.

[13] Daniel J. Paulus, Andrew H. Rogers, Jafar Bakhshaie, Kevin E. Vowles, Michael J. Zvolensky, Pain Severity and Prescription Opioid Misuse among Individuals with Chronic Pain: The Moderating Role of Alcohol Use Severity, Drug and Alcohol Dependence, 10.1016/j.drugalcdep.2019.02.036, (2019).

[14] Desai, Rishi J., et al. "Increase in prescription opioid use during pregnancy among Medicaid-enrolled women." Obstetrics and gynecology 123.5 (2014): 997.

[15] Dowell, Deborah, Tamara M. Haegerich, and Roger Chou. "CDC guideline for prescribing opioids for chronic pain—United States, 2016." Jama 315.15 (2016): 1624-1645.

[16] Fine, Perry G. "Long-term consequences of chronic pain: mounting evidence for pain as a neurological disease and parallels with other chronic disease states." Pain Medicine 12.7 (2011): 9961004.

[17] Foundation, M. o. D. B. D. (2002). March of Dimes updates: is early prenatal care too late? Contemporary Obstetrics and Gynecology, 12, 54-72.

[18] Gau, Jacinta M., and Erika J. Brooke. "An assessment of the impact of a multipronged approach to reducing problematic pain clinics in Florida." Journal of Drug Issues 47.2 (2017): 185-204.

[19] Gihleb, Rania, Osea Giuntella, Ning Zhang. "Prescription drug monitoring programs and neonatal outcomes.” Regional Science and Urban Economics, Volume 81, (2020): 103497, https://doi.org/10.1016/j.regsciurbeco.2019.103497. 
[20] Haight, Sarah C., et al. "Opioid use disorder documented at delivery hospitalization-United States, 1999-2014." Morbidity and Mortality Weekly Report 67.31 (2018): 845.

[21] Horwitz, Jill, et al. The problem of data quality in analyses of opioid regulation: The case of prescription drug monitoring programs. No. w24947. National Bureau of Economic Research, 2018.

[22] Hulse, G. K., et al. "The relationship between maternal use of heroin and methadone and infant birth weight." Addiction92.11 (1997): 1571-1579.

[23] Jilani SM, Frey MT, Pepin D, et al. Evaluation of State-Mandated Reporting of Neonatal Abstinence Syndrome - Six States, 2013-2017. MMWR Morb Mortal Wkly Rep 2019;68:6-10

[24] Jones, Hendrée E., et al. "Cigarette smoking in opioid-dependent pregnant women: neonatal and maternal outcomes." Drug and alcohol dependence 131.3 (2013): 271-277.

[25] Johnson, Kay, et al. "Recommendations to improve preconception health and Health Care-United States: report of the CDC/ATSDR preconception care work group and the select panel on preconception care." Morbidity and Mortality Weekly Report: Recommendations and Reports 55.6 (2006): 1-CE. [26] Kaestner, Robert, and Engy Ziedan. Mortality and Socioeconomic Consequences of Prescription Opioids: Evidence from State Policies. No. w26135. National Bureau of Economic Research, 2019. [27] Kotelchuck, Milton. "The Adequacy of Prenatal Care Utilization Index: its US distribution and association with low birthweight." American journal of public health 84.9 (1994): 1486-1489.

[28] Ko JY, Patrick SW, Tong VT, Patel R, Lind JN, Barfield WD. Incidence of Neonatal Abstinence Syndrome — 28 States, 1999-2013. MMWR Morb Mortal Wkly Rep 2016;65:799-802

[29] Kozhimannil, Katy B., et al. "Nonmedical use of prescription opioids among pregnant US women." Women's Health Issues 27.3 (2017): 308-315.

[30] Lin, Dora H., et al. "Physician attitudes and experiences with Maryland's prescription drug monitoring program (PDMP)." Addiction 112.2 (2017): 311-319. 
[31] Sarka Lisonkova, Lindsay L. Richter, Joseph Ting, Giulia M. Muraca, Qi Wen, Azar Mehrabadi, Sheona Mitchell-Foster, Eugenia Oviedo-Joekes, Janet Lyons. Neonatal Abstinence Syndrome and Associated Neonatal and Maternal Mortality and Morbidity, Pediatrics Aug 2019, 144 (2) e20183664;

DOI: $10.1542 /$ peds.2018-3664

[32] Mallatt, Justine. Prescription Drug Monitoring Programs on Oxycodone Prescriptions, Heroin Substitution, and Crime Rates. No. 1292. Purdue University, Department of Economics, 2017.

[33] Manchikanti, Laxmaiah, Keith R. Brown, and Vijay Singh. "National All Schedules Prescription Electronic Reporting Act (NASPER): balancing substance abuse and medical necessity." Pain Physician 5.3 (2002): 294-319.

[34] Martin JA, Osterman MJ, Kirmeyer SE, Gregory EC. Measuring Gestational Age in Vital Statistics Data: Transitioning to the Obstetric Estimate. Natl Vital Stat Rep. 2015;64(5):1-20.

[35] Moyo, Patience, et al. "Impact of prescription drug monitoring programs (PDMPs) on opioid utilization among Medicare beneficiaries in 10 US States." Addiction 112.10 (2017): 1784-1796.

[36] Murin, Susan, Rokhsara Rafii, and Kathryn Bilello. "Smoking and smoking cessation in pregnancy." Clinics in chest medicine 32.1 (2011): 75-91.

[37] Nielsen, Susan Searles, et al. "Accuracy of prenatal smoking data from Washington State birth certificates in a population-based sample with cotinine measurements." Annals of epidemiology 24.3 (2014): 236-239.

[38] Osmundson, Sarah S., et al. "277: Postpartum opioid prescribing and the risk of persistent opioid use." American Journal of Obstetrics \& Gynecology 220.1 (2019): S197-S198.

[39] Peahl, Alex F., et al. "Rates of new persistent opioid use after vaginal or cesarean birth among US women." JAMA network open 2.7 (2019): e197863-e197863.

[40] Ram, Anita, Michelle Tuten, and Margaret S. Chisolm. "Cigarette smoking reduction in pregnant women with opioid use disorder." Journal of addiction medicine 10.1 (2016): 53. 
[41] Reisman, Richard M., et al. "Prescription opioid usage and abuse relationships: an evaluation of state prescription drug monitoring program efficacy." Substance abuse: research and treatment 3 (2009): SART-S2345.

[42] Rutkow, Lainie, et al. "Effect of Florida's prescription drug monitoring program and pill mill laws on opioid prescribing and use." JAMA internal medicine 175.10 (2015): 1642-1649.

[43] Sanlorenzo, L. A., Stark, A. R., \& Patrick, S. W. (2018). Neonatal abstinence syndrome: an update. Current opinion in pediatrics, 30(2), 182-186. https://doi.org/10.1097/MOP.0000000000000589

[44] Tong, Van T., et al. "Estimates of smoking before and during pregnancy, and smoking cessation during pregnancy: comparing two population-based data sources." Public health reports 128.3 (2013): 179-188.

[45] US Food and Drug Administration. "FDA Drug Safety Communication: FDA has reviewed possible risks of pain medicine use during pregnancy." FDA official site (2015).

[46] Wehby, George L., et al. "Interaction between smoking and body mass index and risk of oral clefts." Annals of epidemiology 27.2 (2017): 103-107.

[47] Weiner, Scott G., et al. "The effect of opioid prescribing guidelines on prescriptions by emergency physicians in Ohio." Annals of emergency medicine 70.6 (2017): 799-808.

[48] Wen, Hefei, et al. "Impact of Medicaid expansion on Medicaid-covered utilization of buprenorphine for opioid use disorder treatment." Medical Care 55.4 (2017): 336-341.

[49] Winkelman, Tyler NA, Virginia W. Chang, and Ingrid A. Binswanger. "Health, polysubstance use, and criminal justice involvement among adults with varying levels of opioid use." JAMA network open 1.3 (2018): e180558-e180558. 
[50] Wachman EM, Schiff DM, Silverstein M. Neonatal Abstinence Syndrome: Advances in Diagnosis and Treatment. JAMA. 2018 Apr 3;319(13):1362-1374. doi: 10.1001/jama.2018.2640. PMID: 29614184.

[51] Witkiewitz, Katie, and Kevin E. Vowles. "Alcohol and opioid use, co-use, and chronic pain in the context of the opioid epidemic: A critical review." Alcoholism: clinical and experimental research 42.3 (2018): 478-488.

[52] Zale, Emily L., Stephen A. Maisto, and Joseph W. Ditre. "Interrelations between pain and alcohol: An integrative review." Clinical psychology review 37 (2015): 57-71. 
Table 1. Female Opioid and Illicit Drug Use by Marital Status and Age (2002-2006)

\begin{tabular}{|l|c|c|c|c|}
\hline & \multicolumn{2}{|c|}{ Unmarried } & \multicolumn{2}{c|}{ Married } \\
& Age 18-25 & Age 26-44 & Age 18-25 & Age 26-44 \\
\hline Any Non-medical Use Pain Reliever Past Year & 0.114 & 0.046 & 0.061 & 0.026 \\
Any Medical Use Pain Reliever Past Year & 0.115 & 0.161 & 0.123 & 0.131 \\
Any Illicit Drug Not Marijuana Past Year & 0.192 & 0.084 & 0.092 & 0.049 \\
\hline
\end{tabular}

Notes - All means except medical use of pain relievers are estimated using data from the 2002 to 2006 National Survey on Drug Use and Health. Mean medical use of pain relievers is from Medical Expenditure Survey from 2002 to 2006. 
Table 2. First Stage Estimates of Effects of PDMPs and Pill Mill Laws on Prescription Opioids

\begin{tabular}{|c|c|c|c|c|c|c|c|c|c|c|c|c|}
\hline \multirow{3}{*}{ Electronic PDMP } & \multicolumn{6}{|c|}{ All Opioids } & \multicolumn{6}{|c|}{ Hydrocodone and Oxycodone } \\
\hline & \multicolumn{3}{|c|}{ Log Total Grams } & \multicolumn{3}{|c|}{ Per- 100 Capita Grams } & \multicolumn{3}{|c|}{ Log Total Grams } & \multicolumn{3}{|c|}{ Per- 100 Capita Grams } \\
\hline & $\begin{array}{c}-0.076 \\
(0.047)\end{array}$ & $\begin{array}{c}-0.050 \\
(0.040)\end{array}$ & $\begin{array}{c}-0.006 \\
(0.047)\end{array}$ & $\begin{array}{c}-0.363 \\
(0.260)\end{array}$ & $\begin{array}{l}-0.205 \\
(0.208)\end{array}$ & $\begin{array}{c}-0.180 \\
(0.300)\end{array}$ & $\begin{array}{l}-0.005 \\
(0.035)\end{array}$ & $\begin{array}{c}0.002 \\
(0.031)\end{array}$ & $\begin{array}{c}0.056^{* *} \\
(0.021)\end{array}$ & $\begin{array}{c}-0.003 \\
(0.213)\end{array}$ & $\begin{array}{c}0.090 \\
(0.200)\end{array}$ & $\begin{array}{c}0.430 * * \\
(0.200)\end{array}$ \\
\hline Modern PDMP & $\begin{array}{c}-0.123^{*} \\
(0.059)\end{array}$ & $\begin{array}{c}-0.113^{*} \\
(0.055)\end{array}$ & $\begin{array}{l}-0.066 \\
(0.043)\end{array}$ & $\begin{array}{c}-1.040^{*} \\
(0.483)\end{array}$ & $\begin{array}{c}-1.074 * \\
(0.400)\end{array}$ & $\begin{array}{c}-0.790 * \\
(0.471)\end{array}$ & $\begin{array}{c}-0.116^{*} \\
(0.06)\end{array}$ & $\begin{array}{c}-0.115^{*} \\
(0.05)\end{array}$ & $\begin{array}{c}-0.083^{*} \\
(0.042)\end{array}$ & $\begin{array}{c}-0.681 \\
(0.460)\end{array}$ & $\begin{array}{c}-0.722 \\
(0.458)\end{array}$ & $\begin{array}{c}-0.600 \\
(0.400)\end{array}$ \\
\hline Pill Mill Law & $\begin{array}{c}-0.151 * \\
(0.075)\end{array}$ & $\begin{array}{c}-0.214 * * \\
(0.076)\end{array}$ & $\begin{array}{c}-0.315^{* *} \\
(0.131)\end{array}$ & $\begin{array}{c}-1.140^{* *} \\
(0.476)\end{array}$ & $\begin{array}{c}-1.377 * * \\
(0.541)\end{array}$ & $\begin{array}{c}-2.530^{*} \\
(1.300)\end{array}$ & $\begin{array}{c}-0.339^{* *} \\
(0.09)\end{array}$ & $\begin{array}{c}-0.368^{* *} \\
(0.094)\end{array}$ & $\begin{array}{c}-0.393^{* *} \\
(0.150)\end{array}$ & $\begin{array}{c}-1.330 * * \\
(0.507)\end{array}$ & $\begin{array}{c}-1.469 * * \\
(0.594)\end{array}$ & $\begin{array}{c}-2.400^{*} \\
(1.300)\end{array}$ \\
\hline $\begin{array}{l}\text { Demographic*Year Controls } \\
\text { State Linear Time Trend } \\
\text { Mean of Dep. Variable } 2003 \\
\text { Number of Observations }\end{array}$ & 4732136 & 4732136 & $\begin{array}{l}\text { Yes } \\
\text { Yes }\end{array}$ & $\begin{array}{c}\text { No } \\
\text { No } \\
3.9 \\
4732136 \\
\end{array}$ & $\begin{array}{c}\text { Yes } \\
\text { No } \\
3.9 \\
4732136\end{array}$ & $\begin{array}{c}\text { Yes } \\
\text { Yes } \\
3.9 \\
4732136\end{array}$ & 4732136 & $\begin{array}{l}\text { Yes } \\
\text { No }\end{array}$ & $\begin{array}{l}\text { Yes } \\
\text { Yes }\end{array}$ & $\begin{array}{c}\text { No } \\
\text { No } \\
2.1 \\
4732136 \\
\end{array}$ & $\begin{array}{c}\text { Yes } \\
\text { No } \\
2.1 \\
4732136 \\
\end{array}$ & $\begin{array}{c}\text { Yes } \\
\text { Yes } \\
2.1 \\
4732136 \\
\end{array}$ \\
\hline
\end{tabular}

Notes: The unit of observation is the year-month-state-demographic cell. Demographic cells are defined based on race/ethnicity (white, black, Hispanic, other/unknown), education (less than high school, high school, some college, college or more, unknown education or education not reported in the state year), age (18-44 individual categories), and marital status (married/unmarried) in a given year. ACROS Opioid grams were calculated at the monthly level by dividing reported quarterly amounts by three. Each mother is matched to the 18 months ACROS opioid amounts in her state of residence (9 months prior to gestation and 9 months after gestation). All regressions include controls for average plurality (order of birth) in the month-year-state-cell, share of male infant in the month- year-state-cell, year of birth fixed effects, month of birth fixed effects and state of residence fixed effects, 18 months state unemployment levels ( 9 months of gestation and 9 months prior to gestation), annual state Medicaid thresholds for pregnant women, and annual state level share of individuals across all ages in poverty. Estimates in second column for each dependent variable add additional controls: the interaction between year dummy variables and mother's age, marital status and education with birth year, 18 months state unemployment levels ( 9 months of gestation and 9 months prior to gestation), annual state Medicaid thresholds for pregnant women, and annual state level share of individuals across all ages in poverty. Estimates in column (3) include all controls in column (2) with the addition of state of residence linear time trends. Standard errors are constructed allowing for non-independence with state $\left(\right.$ cluster on state). ${ }^{+}$indicates $\mathrm{p}$-value $<=0.1, *$ indicates $0.01<\mathrm{p}$-value $<=0.05, * *$ indicates $\mathrm{p}$-value $<=0.01$ 
Table 3. OLS and Instrumental Variables (IV) Estimates of Effects of (Log) Prescription Opioids on Birthweight, Low-birthweight (<2500 g.), Gestational Weeks, and C-Section

\begin{tabular}{|c|c|c|c|c|c|c|c|c|}
\hline Log Grams All Prescription Opioids & \multicolumn{2}{|c|}{ Birthweight } & \multicolumn{2}{|c|}{ Low Birthweight (LBW) } & \multicolumn{2}{|c|}{ Gestational Weeks } & \multicolumn{2}{|c|}{ C-Section } \\
\hline OLS Estimates & $\begin{array}{c}2.34 \\
(2.52)\end{array}$ & $\begin{array}{l}-1.42 \\
(1.45)\end{array}$ & $\begin{array}{c}-0.0001 \\
(0.0004)\end{array}$ & $\begin{array}{c}0.0004 \\
(0.0004)\end{array}$ & $\begin{array}{c}0.028 \\
(0.024)\end{array}$ & $\begin{array}{c}0.0114 \\
(0.0161)\end{array}$ & $\begin{array}{c}-0.002 \\
(0.002)\end{array}$ & $\begin{array}{l}-0.0014 \\
(0.002)\end{array}$ \\
\hline IV Estimates & $\begin{array}{c}-22.63 * * \\
(9.13)\end{array}$ & $\begin{array}{c}-21.72 * * \\
(7.44)\end{array}$ & $\begin{array}{c}0.002 \\
(0.002)\end{array}$ & $\begin{array}{c}0.003 \\
(0.002)\end{array}$ & $\begin{array}{l}0.002 \\
0.035\end{array}$ & $\begin{array}{l}-0.005 \\
(0.035)\end{array}$ & $\begin{array}{l}-0.007 \\
(0.013)\end{array}$ & $\begin{array}{l}-0.0005 \\
(0.008)\end{array}$ \\
\hline Log Grams Hydrocodone \& Oxycodo & & & & & & & & \\
\hline OLS Estimates & $\begin{array}{l}0.039 \\
(2.58)\end{array}$ & $\begin{array}{l}-1.853 \\
(1.98)\end{array}$ & $\begin{array}{l}-0.0006 \\
(0.0005)\end{array}$ & $\begin{array}{c}0.0004 \\
(0.0004)\end{array}$ & $\begin{array}{c}0.014 \\
(0.017)\end{array}$ & $\begin{array}{l}0.0016 \\
(0.014)\end{array}$ & $\begin{array}{c}0.002 \\
(0.002)\end{array}$ & $\begin{array}{c}0.0033 \\
(0.0021)\end{array}$ \\
\hline IV Estimates & $\begin{array}{c}-12.71 * \\
(6.03)\end{array}$ & $\begin{array}{c}-12.45^{* *} \\
(3.59)\end{array}$ & $\begin{array}{l}0.0003 \\
(0.001)\end{array}$ & $\begin{array}{c}0.002 \\
(0.001)\end{array}$ & $\begin{array}{l}0.008+ \\
(0.027)\end{array}$ & $\begin{array}{c}0.003 \\
(0.024)\end{array}$ & $\begin{array}{c}-0.006 \\
(0.006)\end{array}$ & $\begin{array}{l}-0.002 \\
(0.005)\end{array}$ \\
\hline $\begin{array}{l}\text { Demographic*Year Controls } \\
\text { Mean of Dep. Var. in } 2003 \\
\text { Standard Dev. for Cont. Outcomes } \\
\text { Number of Observations }\end{array}$ & $\begin{array}{c}\text { No } \\
3220.9 \\
(605) \\
4732136\end{array}$ & $\begin{array}{c}\text { Yes } \\
3220.9 \\
(605) \\
4732136\end{array}$ & $\begin{array}{c}\text { No } \\
0.111 \\
4732136\end{array}$ & $\begin{array}{c}\text { Yes } \\
0.111 \\
4732136\end{array}$ & $\begin{array}{c}\text { No } \\
38.78 \\
(5.2) \\
4732136\end{array}$ & $\begin{array}{c}\text { Yes } \\
38.78 \\
(5.2) \\
4732136\end{array}$ & $\begin{array}{c}\text { No } \\
0.329 \\
4732136\end{array}$ & $\begin{array}{c}\text { Yes } \\
0.329\end{array}$ \\
\hline
\end{tabular}

Notes: The unit of observation is the year-month-state-demographic cell. Demographic cells are defined based on race/ethnicity (white, black, Hispanic, other/unknown), education (less than high school, high school, some college, college or more, unknown education or education not reported in the state year), age (18-44 individual categories), and marital status (married/unmarried) in a given year. All regressions include controls for average plurality (order of birth) in the month-year-state-cell, share of male infant in the monthyear-state-cell, year of birth fixed effects, month of birth fixed effects and state of residence fixed effects, 18 months state unemployment levels ( 9 months of gestation and 9 months prior to gestation), annual state Medicaid thresholds for pregnant women, and annual state level share of individuals across all ages in poverty. Estimates in second column for each dependent variable add additional controls: the interaction between year dummy variables and mother's age, marital status and education with birth year, 18 months state unemployment levels ( 9 months of gestation and 9 months prior to gestation), annual state Medicaid thresholds for pregnant women, and annual state level share of individuals across all ages in poverty. Estimates in column (3) include all controls in column (2) with the addition of state of residence linear time trends. Standard errors are constructed allowing for non-independence with state (cluster on state). ${ }^{+}$indicates p-value $<=0.1, *$ indicates $0.01<$ p-value $<=0.05, * *$ indicates $\mathrm{p}$-value $<=0.01$ 
Table 4. OLS and Instrumental Variables (IV) Estimates of Effects of (Log) Prescription Opioids on Prenatal Visits, Smoking during Pregnancy, and Weight Gain

\begin{tabular}{|c|c|c|c|c|c|c|}
\hline Log Grams All Prescription Opioids & $\begin{array}{c}\text { Number Prenatal } \\
\text { Visits } \\
\end{array}$ & $\begin{array}{c}\text { First Trimester } \\
\text { Visit }\end{array}$ & $\begin{array}{c}\text { Inadequate } \\
\text { Prenatal Care }\end{array}$ & $\begin{array}{c}\text { Smoked During } \\
\text { Pregnancy }\end{array}$ & $\begin{array}{c}\text { Weight Gain }<20 \\
\text { lbs. }\end{array}$ & $\begin{array}{c}\text { Weight gain }>40 \\
\text { lbs. }\end{array}$ \\
\hline OLS Estimates & $\begin{array}{c}0.145 \\
(0.111)\end{array}$ & $\begin{array}{c}0.009 \\
(0.011)\end{array}$ & $\begin{array}{l}-0.007 \\
(0.010)\end{array}$ & $\begin{array}{l}-0.0004 \\
(0.002)\end{array}$ & $\begin{array}{l}-0.041^{*} \\
(0.018)\end{array}$ & $\begin{array}{c}0.09 \\
(0.06)\end{array}$ \\
\hline $\begin{array}{l}\text { IV Estimates } \\
\text { Log Grams Hydrocodone \& Oxycodone }\end{array}$ & $\begin{array}{l}0.510 \\
(0.45)\end{array}$ & $\begin{array}{l}-0.125^{*} \\
(0.064)\end{array}$ & $\begin{array}{l}0.083^{*} \\
(0.043)\end{array}$ & $\begin{array}{c}0.014 \\
(0.016)\end{array}$ & $\begin{array}{l}-0.033 \\
(0.024)\end{array}$ & $\begin{array}{c}0.09 \\
(0.07)\end{array}$ \\
\hline OLS Estimates & $\begin{array}{c}0.168 \\
(0.128)\end{array}$ & $\begin{array}{l}-0.022+ \\
(0.012)\end{array}$ & $\begin{array}{c}0.015 \\
(0.012)\end{array}$ & $\begin{array}{l}0.008+ \\
(0.004)\end{array}$ & $\begin{array}{c}-0.026+ \\
(0.014)\end{array}$ & $\begin{array}{c}0.065 \\
(0.045)\end{array}$ \\
\hline IV Estimates & $\begin{array}{c}0.381 \\
(0.302)\end{array}$ & $\begin{array}{l}-0.081^{*} \\
(0.033)\end{array}$ & $\begin{array}{l}0.045^{*} \\
(0.020)\end{array}$ & $\begin{array}{l}0.012 \\
(0.01)\end{array}$ & $\begin{array}{c}0.003 \\
(0.021)\end{array}$ & $\begin{array}{l}-0.018 \\
(0.05)\end{array}$ \\
\hline $\begin{array}{l}\text { Demographic*Year Controls } \\
\text { Mean of Dep. Var. in } 2003 \\
\text { Standard Dev. for Cont. Outcomes } \\
\text { Number of Observations }\end{array}$ & $\begin{array}{c}\text { Yes } \\
10.9 \\
(3.23) \\
4630517\end{array}$ & $\begin{array}{c}\text { Yes } \\
0.77 \\
4538249\end{array}$ & $\begin{array}{c}\text { Yes } \\
0.15 \\
4538249\end{array}$ & $\begin{array}{c}\text { Yes } \\
0.13 \\
4172273\end{array}$ & $\begin{array}{c}\text { Yes } \\
0.25 \\
4738863\end{array}$ & $\begin{array}{c}\text { Yes } \\
0.32 \\
4738863\end{array}$ \\
\hline
\end{tabular}

Notes: The unit of observation is the year-month-state-demographic cell. Demographic cells are defined based on race/ethnicity (white, black, Hispanic, other/unknown), education (less than high school, high school, some college, college or more, unknown education or education not reported in the state year), age (18-44 individual categories), and marital status (married/unmarried) in a given year. All regressions include controls for average plurality (order of birth) in the month-year-state-cell, share of male infant in the monthyear-state-cell, year of birth fixed effects, month of birth fixed effects and state of residence fixed effects, 18 months state unemployment levels (9 months of gestation and 9 months prior to gestation), annual state Medicaid thresholds for pregnant women, and annual state level share of individuals across all ages in poverty. All estimates also include the interaction between year dummy variables and mother's age, marital status and education with birth year, 18 months state unemployment levels ( 9 months of gestation and 9 months prior to gestation), annual state Medicaid thresholds for pregnant women, and annual state level share of individuals across all ages in poverty. Standard errors are constructed allowing for non-independence with state (cluster on state) ${ }^{+}$indicates p-value $<=0.1, *$ indicates $0.01<$ p-value $<=0.05, * *$ indicates $\mathrm{p}$-value $<=0.01$ 
Table 5. Reduced Form Estimates of Effects of PDMPs and Pill Mill Laws on Birthweight, Low-birthweight ( $<2500$ g.), Gestational Weeks, and C-Section

\begin{tabular}{|c|c|c|c|c|}
\hline & Birthweight & Low Birthweight (LBW) & Gestational Weeks & C-Section \\
\hline Electronic PDMP & $\begin{array}{l}1.408 \\
(1.310)\end{array}$ & $\begin{array}{c}-0.0002 \\
(0.0003)\end{array}$ & $\begin{array}{c}0.008 \\
(0.011)\end{array}$ & $\begin{array}{l}-0.0009 \\
(0.002)\end{array}$ \\
\hline Modern PDMP & $\begin{array}{l}2.680+ \\
(1.552)\end{array}$ & $\begin{array}{l}-0.0009+ \\
(0.0005)\end{array}$ & $\begin{array}{c}0.022 \\
(0.013)\end{array}$ & $\begin{array}{l}-0.004 \\
(0.002)\end{array}$ \\
\hline Pill Mill & $\begin{array}{c}4.576^{* *} \\
(1.148)\end{array}$ & $\begin{array}{l}-0.0004 \\
(0.0005)\end{array}$ & $\begin{array}{l}-0.011 \\
(0.013)\end{array}$ & $\begin{array}{c}0.003 \\
(0.002)\end{array}$ \\
\hline $\begin{array}{l}\text { Demographic*Year Controls } \\
\text { State Linear Time Trend } \\
\text { Mean of Dep. Var. in } 2003 \\
\text { Standard Dev. for Cont. Outcomes } \\
\text { Number of Observations }\end{array}$ & $\begin{array}{c}\text { Yes } \\
\text { No } \\
3220.9 \\
(605) \\
4732136\end{array}$ & $\begin{array}{c}\text { Yes } \\
\text { No } \\
0.111 \\
4732136\end{array}$ & $\begin{array}{c}\text { Yes } \\
\text { No } \\
38.78 \\
(5.2) \\
4732136\end{array}$ & $\begin{array}{c}\text { Yes } \\
\text { No } \\
0.329 \\
4732136\end{array}$ \\
\hline
\end{tabular}

Notes: The unit of observation is the year-month-state-demographic cell. Demographic cells are defined based on race/ethnicity (white, black, Hispanic, other/unknown), education (less than high school, high school, some college, college or more, unknown education or education not reported in the state year), age (18-44 individual categories), and marital status (married/unmarried) in a given year. All regressions include controls for average plurality (order of birth) in the month-year-state-cell, share of male infant in the monthyear-state-cell, year of birth fixed effects, month of birth fixed effects and state of residence fixed effects, 18 months state unemployment levels (9 months of gestation and 9 months prior to gestation), annual state Medicaid thresholds for pregnant women, and annual state level share of individuals across all ages in poverty. All estimates also include the interaction between year dummy variables and mother's age, marital status and education with birth year, 18 months state unemployment levels $(9$ months of gestation and 9 months prior to gestation), annual state Medicaid thresholds for pregnant women, and annual state level share of individuals across all ages in poverty. Standard errors are constructed allowing for non-independence with state (cluster on state) ${ }^{+}$indicates p-value $<=0.1, *$ indicates $0.01<$ p-value $<=0.05, * *$ indicates $p$-value $<=0.01$ 
Table 6. Reduced Form Estimates of Effects of PDMPs and Pill Mill Laws on Prenatal Visits, Smoking during Pregnancy, and Weight Gain

\begin{tabular}{|c|c|c|c|c|c|c|}
\hline & $\begin{array}{c}\text { Number Prenatal } \\
\text { Visits }\end{array}$ & $\begin{array}{c}\text { First Trimester } \\
\text { Visit } \\
\end{array}$ & $\begin{array}{c}\text { Inadequate } \\
\text { Prenatal Care }\end{array}$ & $\begin{array}{c}\text { Smoked During } \\
\text { Pregnancy }\end{array}$ & $\begin{array}{c}\text { Weight Gain }<20 \\
\text { lbs. }\end{array}$ & $\begin{array}{c}\text { Weight gain }>40 \\
\text { lbs. }\end{array}$ \\
\hline Electronic PDMP & $\begin{array}{c}0.098 \\
(0.085)\end{array}$ & $\begin{array}{c}0.004 \\
(0.011)\end{array}$ & $\begin{array}{l}-0.009 \\
(0.013)\end{array}$ & $\begin{array}{c}0.0032 \\
(0.0029)\end{array}$ & $\begin{array}{l}0.026+ \\
(0.015)\end{array}$ & $\begin{array}{l}-0.075 \\
(0.051)\end{array}$ \\
\hline Modern PDMP & $\begin{array}{l}-0.145 \\
(0.139)\end{array}$ & $\begin{array}{c}0.003 \\
(0.014)\end{array}$ & $\begin{array}{l}-0.01 \\
(0.02)\end{array}$ & $\begin{array}{c}0.0026 \\
(0.0042)\end{array}$ & $\begin{array}{c}0.0328+ \\
(0.019)\end{array}$ & $\begin{array}{l}-0.101 \\
(0.06)\end{array}$ \\
\hline Pill Mill & $\begin{array}{l}-0.024 \\
(0.114)\end{array}$ & $\begin{array}{c}0.037 * * \\
(0.013)\end{array}$ & $\begin{array}{c}-0.019 * \\
(0.008)\end{array}$ & $\begin{array}{l}-0.0037 \\
(0.0028)\end{array}$ & $\begin{array}{l}-0.009 \\
(0.012)\end{array}$ & $\begin{array}{l}0.031 \\
(0.03)\end{array}$ \\
\hline $\begin{array}{l}\text { Demographic*Year Controls } \\
\text { Mean of Dep. Var. in } 2003 \\
\text { Standard Dev. for Cont. Outcomes } \\
\text { Number of Observations }\end{array}$ & $\begin{array}{c}\text { Yes } \\
10.9 \\
(3.23) \\
4630517\end{array}$ & $\begin{array}{c}\text { Yes } \\
0.77 \\
4538249\end{array}$ & $\begin{array}{c}\text { Yes } \\
0.15 \\
4538249\end{array}$ & $\begin{array}{c}\text { Yes } \\
0.13 \\
4172273\end{array}$ & $\begin{array}{c}\text { Yes } \\
0.25 \\
4738863\end{array}$ & $\begin{array}{c}\text { Yes } \\
0.32 \\
4738863\end{array}$ \\
\hline
\end{tabular}

Notes: The unit of observation is the year-month-state-demographic cell. Demographic cells are defined based on race/ethnicity (white, black, Hispanic, other/unknown), education (less than high school, high school, some college, college or more, unknown education or education not reported in the state year), age (18-44 individual categories), and marital status (married/unmarried) in a given year. All regressions include controls for average plurality (order of birth) in the month-year-state-cell, share of male infant in the monthyear-state-cell, year of birth fixed effects, month of birth fixed effects and state of residence fixed effects, 18 months state unemployment levels (9 months of gestation and 9 months prior to gestation), annual state Medicaid thresholds for pregnant women, and annual state level share of individuals across all ages in poverty. All estimates also include the interaction between year dummy variables and mother's age, marital status and education with birth year, 18 months state unemployment levels $(9$ months of gestation and 9 months prior to gestation), annual state Medicaid thresholds for pregnant women, and annual state level share of individuals across all ages in poverty. Standard errors are constructed allowing for non-independence with state (cluster on state) ${ }^{+}$indicates p-value $<=0.1, *$ indicates $0.01<$ p-value $<=0.05, * *$ indicates $p$-value $<=0.01$ 
Table 7. OLS and Instrumental Variables (IV) Estimates of Effects of (Log) Prescription Opioids on Birthweight, Low-birthweight ( $<2500$ g.), Gestational Weeks, and C-Section Sample of Unmarried Mothers

\begin{tabular}{|c|c|c|c|c|c|c|c|c|}
\hline \multirow[b]{2}{*}{ Log Grams All Prescription Opioids } & \multicolumn{4}{|c|}{ Ages 18 to 25} & \multicolumn{4}{|c|}{ Ages 26 to 44} \\
\hline & Birthweight & LBW & $\begin{array}{c}\text { Gestational } \\
\text { Weeks }\end{array}$ & C-Section & Birthweight & LBW & $\begin{array}{c}\text { Gestational } \\
\text { Weeks }\end{array}$ & C-Section \\
\hline OLS Estimates & $\begin{array}{c}-2.224 \\
(1.843)\end{array}$ & $\begin{array}{c}0.0007 \\
(0.0007)\end{array}$ & $\begin{array}{l}0.00672 \\
(0.0176)\end{array}$ & $\begin{array}{c}-0.0012 \\
(0.0017)\end{array}$ & $\begin{array}{l}-3.46 \\
(2.28)\end{array}$ & $\begin{array}{c}0.0004 \\
(0.0009)\end{array}$ & $\begin{array}{l}0.005 \\
(0.02)\end{array}$ & $\begin{array}{c}-0.0018 \\
(0.0026)\end{array}$ \\
\hline IV Estimates & $\begin{array}{c}-14.3+ \\
(8.06)\end{array}$ & $\begin{array}{c}0.0024 \\
(0.0026)\end{array}$ & $\begin{array}{c}0.020 \\
(0.038)\end{array}$ & $\begin{array}{c}-0.001 \\
(0.008)\end{array}$ & $\begin{array}{l}-16.2^{*} \\
(7.13)\end{array}$ & $\begin{array}{l}0.0008 \\
(0.003)\end{array}$ & $\begin{array}{c}0.008 \\
(0.042)\end{array}$ & $\begin{array}{l}-0.001 \\
(0.007)\end{array}$ \\
\hline Log Grams Hydrocodone \& Oxycodo & & & & & & & & \\
\hline OLS Estimates & $\begin{array}{l}-0.450 \\
(2.183)\end{array}$ & $\begin{array}{c}-0.0003 \\
(0.0007)\end{array}$ & $\begin{array}{l}-0.0005 \\
(0.015)\end{array}$ & $\begin{array}{l}0.0019 \\
(0.002)\end{array}$ & $\begin{array}{l}-3.001 \\
(2.465)\end{array}$ & $\begin{array}{c}-0.0007 \\
(0.0008)\end{array}$ & $\begin{array}{l}-0.003 \\
(0.016)\end{array}$ & $\begin{array}{c}0.004 \\
(0.002)\end{array}$ \\
\hline IV Estimates & $\begin{array}{c}-9.35^{*} \\
(4.31)\end{array}$ & $\begin{array}{c}.0020 \\
(0.002)\end{array}$ & $\begin{array}{c}0.0123 \\
(0.0288)\end{array}$ & $\begin{array}{c}-0.0052 \\
(0.0051)\end{array}$ & $\begin{array}{c}-10.47 * * \\
(3.92)\end{array}$ & $\begin{array}{l}0.0003 \\
(0.002)\end{array}$ & $\begin{array}{c}0.01 \\
(0.03)\end{array}$ & $\begin{array}{l}-0.001 \\
(0.005)\end{array}$ \\
\hline $\begin{array}{l}\text { Demographic*Year Controls } \\
\text { Mean of Dep. Var. in } 2003 \\
\text { Standard Dev. for Cont. Outcomes } \\
\text { Number of Observations }\end{array}$ & $\begin{array}{c}\text { Yes } \\
3140 \\
(512) \\
855,409\end{array}$ & $\begin{array}{c}\text { Yes } \\
0.116 \\
855,409\end{array}$ & $\begin{array}{c}\text { Yes } \\
38.2 \\
(2.86) \\
855,409\end{array}$ & $\begin{array}{c}\text { Yes } \\
0.24 \\
855,409\end{array}$ & $\begin{array}{c}\text { Yes } \\
3161 \\
(574) \\
1379725\end{array}$ & $\begin{array}{c}\text { Yes } \\
0.13 \\
1379725\end{array}$ & $\begin{array}{c}\text { Yes } \\
38.2 \\
(2.80) \\
1379725\end{array}$ & $\begin{array}{l}\text { Yes } \\
0.36\end{array}$ \\
\hline
\end{tabular}

Notes: The unit of observation is the year-month-state-demographic cell. Demographic cells are defined based on race/ethnicity (white, black, Hispanic, other/unknown), education (less than high school, high school, some college, college or more, unknown education or education not reported in the state year), age (18-44 individual categories), and marital status (married/unmarried) in a given year. All regressions include controls for average plurality (order of birth) in the month-year-state-cell, share of male infant in the monthyear-state-cell, year of birth fixed effects, month of birth fixed effects and state of residence fixed effects, 18 months state unemployment levels ( 9 months of gestation and 9 months prior to gestation), annual state Medicaid thresholds for pregnant women, and annual state level share of individuals across all ages in poverty. All estimates also include the interaction between year dummy variables and mother's age, marital status and education with birth year, 18 months state unemployment levels $(9$ months of gestation and 9 months prior to gestation), annual state Medicaid thresholds for pregnant women, and annual state level share of individuals across all ages in poverty. Standard errors are constructed allowing for non-independence with state (cluster on state). ${ }^{+}$indicates p-value $<=0.1, *$ indicates $0.01<$ p-value $<=0.05, * *$ indicates $p$-value $<=0.01$ 
Table 8. OLS and Instrumental Variables (IV) Estimates of Effects of (Log) Prescription Opioids on Birthweight, Low-birthweight (<2500 g.), Gestational Weeks, and C-Section, 2003-2016 Sample of Married Mothers

\begin{tabular}{|c|c|c|c|c|c|c|c|c|}
\hline \multirow[b]{2}{*}{ Log Grams All Prescription Opioids } & \multicolumn{4}{|c|}{ Ages 18 to 25} & \multicolumn{4}{|c|}{ Ages 26 to 44} \\
\hline & Birthweight & LBW & $\begin{array}{c}\text { Gestational } \\
\text { Weeks }\end{array}$ & C-Section & Birthweight & LBW & $\begin{array}{c}\text { Gestational } \\
\text { Weeks }\end{array}$ & C-Section \\
\hline OLS Estimates & $\begin{array}{l}-1.847 \\
(1.771)\end{array}$ & $\begin{array}{c}0.0001 \\
(0.0006)\end{array}$ & $\begin{array}{l}0.0221 \\
(0.018)\end{array}$ & $\begin{array}{r}-0.00142 \\
(0.0022)\end{array}$ & $\begin{array}{c}-0.688 \\
(1.738)\end{array}$ & $\begin{array}{c}0.0004 \\
(0.0005)\end{array}$ & $\begin{array}{c}0.0138 \\
(0.0153)\end{array}$ & $\begin{array}{c}-0.0003 \\
(0.0027)\end{array}$ \\
\hline IV Estimates & $\begin{array}{l}-26.6^{*} \\
(13.9)\end{array}$ & $\begin{array}{l}0.007+ \\
(0.004)\end{array}$ & $\begin{array}{l}-0.039 \\
(0.052)\end{array}$ & $\begin{array}{l}-0.005 \\
(0.013)\end{array}$ & $\begin{array}{c}-23.5^{* *} \\
(7.46)\end{array}$ & $\begin{array}{c}0.003 \\
(0.002)\end{array}$ & $\begin{array}{c}-0.014 \\
(0.036)\end{array}$ & $\begin{array}{c}0.01 \\
(0.011)\end{array}$ \\
\hline Log Grams Hydrocodone \& Oxycodo & & & & & & & & \\
\hline OLS Estimates & $\begin{array}{c}-0.174 \\
(2.461)\end{array}$ & $\begin{array}{c}0.000001 \\
(0.0008)\end{array}$ & $\begin{array}{l}0.0101 \\
(0.016)\end{array}$ & $\begin{array}{l}0.0036 \\
(0.002)\end{array}$ & $\begin{array}{l}-2.462 \\
(2.462)\end{array}$ & $\begin{array}{c}0.0009^{*} \\
(0.0004)\end{array}$ & $\begin{array}{l}0.0023 \\
(0.014)\end{array}$ & $\begin{array}{l}0.0056+ \\
(0.0029)\end{array}$ \\
\hline IV Estimates & $\begin{array}{c}-12.95+ \\
(7.34)\end{array}$ & $\begin{array}{l}0.003+ \\
(0.001)\end{array}$ & $\begin{array}{l}-0.014 \\
(0.037)\end{array}$ & $\begin{array}{l}-0.004 \\
(0.007)\end{array}$ & $\begin{array}{c}-13.53^{* *} \\
(4.08)\end{array}$ & $\begin{array}{l}0.0014 \\
(0.001)\end{array}$ & $\begin{array}{c}-0.002 \\
(0.025)\end{array}$ & $\begin{array}{c}0.003 \\
(0.006)\end{array}$ \\
\hline $\begin{array}{l}\text { Demographic*Year Controls } \\
\text { Mean of Dep. Var. in } 2003 \\
\text { Standard Dev. for Cont. Outcomes } \\
\text { Number of Observations }\end{array}$ & $\begin{array}{c}\text { Yes } \\
3220 \\
(465) \\
691350\end{array}$ & $\begin{array}{c}\text { Yes } \\
0.089 \\
691350\end{array}$ & $\begin{array}{c}\text { Yes } \\
38.6 \\
(2.4) \\
691350\end{array}$ & $\begin{array}{c}\text { Yes } \\
0.238 \\
691350\end{array}$ & $\begin{array}{c}\text { Yes } \\
3266 \\
(598) \\
1805652\end{array}$ & $\begin{array}{c}\text { Yes } \\
0.102 \\
1805652\end{array}$ & $\begin{array}{c}\text { Yes } \\
38.7 \\
(5.0) \\
1805652\end{array}$ & $\begin{array}{c}\text { Yes } \\
0.365 \\
1805652\end{array}$ \\
\hline
\end{tabular}

Notes: The unit of observation is the year-month-state-demographic cell. Demographic cells are defined based on race/ethnicity (white, black, Hispanic, other/unknown), education (less than high school, high school, some college, college or more, unknown education or education not reported in the state year), age (18-44 individual categories), and marital status (married/unmarried) in a given year. All regressions include controls for average plurality (order of birth) in the month-year-state-cell, share of male infant in the monthyear-state-cell, year of birth fixed effects, month of birth fixed effects and state of residence fixed effects, 18 months state unemployment levels ( 9 months of gestation and 9 months prior to gestation), annual state Medicaid thresholds for pregnant women, and annual state level share of individuals across all ages in poverty. All estimates also include the interaction between year dummy variables and mother's age, marital status and education with birth year, 18 months state unemployment levels $(9$ months of gestation and 9 months prior to gestation), annual state Medicaid thresholds for pregnant women, and annual state level share of individuals across all ages in poverty. Standard errors are constructed allowing for non-independence with state (cluster on state). ${ }^{+}$indicates p-value $<=0.1, *$ indicates $0.01<$ p-value $<=0.05, * *$ indicates $p$-value $<=0.01$ 
Table 9. OLS and Instrumental Variables (IV) Estimates of Effects of (Log) Prescription Opioids on Prenatal Visits, Smoking during Pregnancy, and Weight Gain Sample of Unmarried Mothers

\begin{tabular}{|c|c|c|c|c|c|c|c|c|c|c|c|c|}
\hline & \multicolumn{6}{|c|}{ Ages 18 to 25} & \multicolumn{6}{|c|}{ Ages 26 to 44} \\
\hline $\begin{array}{l}\text { Log Grams All } \\
\text { Prescription Opioids }\end{array}$ & $\begin{array}{c}\text { Number } \\
\text { Prenatal } \\
\text { Visits }\end{array}$ & $\begin{array}{l}\text { First } \\
\text { Trim. } \\
\text { Visit }\end{array}$ & $\begin{array}{c}\text { Inadeq. } \\
\text { Prenatal } \\
\text { Care }\end{array}$ & $\begin{array}{c}\text { Smoked } \\
\text { During } \\
\text { Preg. }\end{array}$ & $\begin{array}{c}\text { Weight } \\
\text { Gain }<20 \\
\text { lbs. }\end{array}$ & $\begin{array}{c}\text { Weight } \\
\text { gain }>40 \\
\text { lbs. }\end{array}$ & $\begin{array}{c}\text { Number } \\
\text { Prenatal } \\
\text { Visits }\end{array}$ & $\begin{array}{l}\text { First } \\
\text { Trim. } \\
\text { Visit }\end{array}$ & $\begin{array}{c}\text { Inadeq. } \\
\text { Prenatal } \\
\text { Care }\end{array}$ & $\begin{array}{c}\text { Smoked } \\
\text { During } \\
\text { Preg. }\end{array}$ & $\begin{array}{c}\text { Weight } \\
\text { Gain }<20 \\
\text { lbs. }\end{array}$ & $\begin{array}{c}\text { Weight } \\
\text { gain }>40 \\
\text { lbs. }\end{array}$ \\
\hline OLS Estimates & $\begin{array}{c}0.189 \\
(0.121)\end{array}$ & $\begin{array}{c}0.014 \\
(0.018)\end{array}$ & $\begin{array}{l}-0.010 \\
(0.014)\end{array}$ & $\begin{array}{c}0.002 \\
(0.004)\end{array}$ & $\begin{array}{l}-0.039^{*} \\
(0.017)\end{array}$ & $\begin{array}{c}0.073 \\
(0.049)\end{array}$ & $\begin{array}{l}0.180 \\
(0.124)\end{array}$ & $\begin{array}{c}0.006 \\
(0.015)\end{array}$ & $\begin{array}{l}-0.004 \\
(0.013)\end{array}$ & $\begin{array}{l}-0.002 \\
(0.004)\end{array}$ & $\begin{array}{l}-0.052 * \\
(0.021)\end{array}$ & $\begin{array}{c}0.089 \\
(0.054)\end{array}$ \\
\hline IV Estimates & $\begin{array}{l}-0.188 \\
(0.516)\end{array}$ & $\begin{array}{l}-0.212 * \\
(0.093)\end{array}$ & $\begin{array}{c}0.128 \\
(0.056)\end{array}$ & $\begin{array}{c}0.031 \\
(0.026)\end{array}$ & $\begin{array}{l}-0.041+ \\
(0.023)\end{array}$ & $\begin{array}{l}0.084 \\
(0.06)\end{array}$ & $\begin{array}{c}0.223 \\
(0.455)\end{array}$ & $\begin{array}{l}-0.151^{*} \\
(0.070)\end{array}$ & $\begin{array}{l}0.098^{*} \\
(0.046)\end{array}$ & $\begin{array}{c}0.023 \\
(0.025)\end{array}$ & $\begin{array}{l}-0.034 \\
(0.025)\end{array}$ & $\begin{array}{c}0.070 \\
(0.060)\end{array}$ \\
\hline $\begin{array}{l}\text { Log Grams Hydrocodone } \\
\& \text { Oxycodone }\end{array}$ & & & & & & & & & & & & \\
\hline OLS Estimates & $\begin{array}{c}0.103 \\
(0.114)\end{array}$ & $\begin{array}{c}-0.032+ \\
(0.017)\end{array}$ & $\begin{array}{c}0.023 \\
(0.014)\end{array}$ & $\begin{array}{c}0.017 * * \\
(0.006)\end{array}$ & $\begin{array}{c}-0.027^{*} \\
(0.014)\end{array}$ & $\begin{array}{c}0.055 \\
(0.039)\end{array}$ & $\begin{array}{l}0.209+ \\
(0.125)\end{array}$ & $\begin{array}{c}-0.028^{*} \\
(0.013)\end{array}$ & $\begin{array}{c}0.019 \\
(0.013)\end{array}$ & $\begin{array}{c}0.0127^{*} \\
(0.006)\end{array}$ & $\begin{array}{c}-0.033^{*} \\
(0.016)\end{array}$ & $\begin{array}{c}0.064 \\
(0.041)\end{array}$ \\
\hline IV Estimates & $\begin{array}{l}-0.075 \\
(0.306)\end{array}$ & $\begin{array}{c}-0.141 * * \\
(0.050\end{array}$ & $\begin{array}{c}0.075^{* *} \\
(0.025)\end{array}$ & $\begin{array}{c}0.022 \\
(0.015)\end{array}$ & $\begin{array}{l}-0.007 \\
(0.017)\end{array}$ & $\begin{array}{c}-0.001 \\
(0.034)\end{array}$ & $\begin{array}{c}0.202 \\
(0.310)\end{array}$ & $\begin{array}{c}-0.098 * * \\
(0.04)\end{array}$ & $\begin{array}{l}0.056^{*} \\
(0.023)\end{array}$ & $\begin{array}{c}0.020 \\
(0.014)\end{array}$ & $\begin{array}{l}-0.005 \\
(0.021)\end{array}$ & $\begin{array}{c}0.004 \\
(0.037)\end{array}$ \\
\hline $\begin{array}{l}\text { Demographic*Year } \\
\text { Controls }\end{array}$ & Yes & Yes & Yes & Yes & Yes & Yes & Yes & Yes & Yes & Yes & Yes & Yes \\
\hline $\begin{array}{l}\text { Mean of Dep. Var. in } 2003 \\
\text { Standard Deviation }\end{array}$ & $\begin{array}{l}10.2 \\
(3.0)\end{array}$ & 0.77 & 0.15 & 0.19 & 0.22 & 0.36 & $\begin{array}{l}10.5 \\
(3.6)\end{array}$ & 0.77 & 0.15 & 0.21 & 0.27 & 0.33 \\
\hline Number of Observations & 838578 & 822170 & 822170 & 767393 & 856496 & 856496 & 1344255 & 1318561 & 1318561 & 1213416 & 1381638 & 1381638 \\
\hline
\end{tabular}

Notes: The unit of observation is the year-month-state-demographic cell. Demographic cells are defined based on race/ethnicity (white, black, Hispanic, other/unknown), education (less than high school, high school, some college, college or more, unknown education or education not reported in the state year), age (18-44 individual categories), and marital status (married/unmarried) in a given year. All regressions include controls for average plurality (order of birth) in the month-year-state-cell, share of male infant in the monthyear-state-cell, year of birth fixed effects, month of birth fixed effects and state of residence fixed effects, 18 months state unemployment levels ( 9 months of gestation and 9 months prior to gestation), annual state Medicaid thresholds for pregnant women, and annual state level share of individuals across all ages in poverty. All estimates also include the interaction between year dummy variables and mother's age, marital status and education with birth year, 18 months state unemployment levels ( 9 months of gestation and 9 months prior to gestation), annual state Medicaid thresholds for pregnant women, and annual state level share of individuals across all ages in poverty. Standard errors are constructed allowing for non-independence with state (cluster on state). ${ }^{+}$indicates p-value $<=0.1,{ }^{*}$ indicates $0.01<$ p-value $<=0.05,{ }^{* *}$ indicates p-value $<=0.01$ 
Table 10. OLS and Instrumental Variables (IV) Estimates of Effects of (Log) Prescription Opioids on Prenatal Visits, Smoking during Pregnancy, and Weight Gain Sample of Married Mothers

\begin{tabular}{|c|c|c|c|c|c|c|c|c|c|c|c|c|}
\hline & \multicolumn{6}{|c|}{ Ages 18 to 25} & \multicolumn{6}{|c|}{ Ages 26 to 44} \\
\hline $\begin{array}{l}\text { Log Grams All } \\
\text { Prescription Opioids }\end{array}$ & $\begin{array}{c}\text { Number } \\
\text { Prenatal } \\
\text { Visits }\end{array}$ & $\begin{array}{l}\text { First } \\
\text { Trim. } \\
\text { Visit }\end{array}$ & $\begin{array}{c}\text { Inadeq. } \\
\text { Prenatal } \\
\text { Care }\end{array}$ & $\begin{array}{c}\text { Smoked } \\
\text { During } \\
\text { Preg. }\end{array}$ & $\begin{array}{c}\text { Weight } \\
\text { Gain }<20 \\
\text { lbs. }\end{array}$ & $\begin{array}{c}\text { Weight } \\
\text { gain }>40 \\
\text { lbs. }\end{array}$ & $\begin{array}{c}\text { Number } \\
\text { Prenatal } \\
\text { Visits }\end{array}$ & $\begin{array}{l}\text { First } \\
\text { Trim. } \\
\text { Visit }\end{array}$ & $\begin{array}{c}\text { Inadeq. } \\
\text { Prenatal } \\
\text { Care }\end{array}$ & $\begin{array}{c}\text { Smoked } \\
\text { During } \\
\text { Preg. }\end{array}$ & $\begin{array}{c}\text { Weight } \\
\text { Gain }<20 \\
\text { lbs. }\end{array}$ & $\begin{array}{c}\text { Weight } \\
\text { gain }>40 \\
\text { lbs. }\end{array}$ \\
\hline OLS Estimates & $\begin{array}{l}0.203+ \\
(0.111)\end{array}$ & $\begin{array}{c}0.014 \\
(0.012)\end{array}$ & $\begin{array}{l}-0.012 \\
(0.01)\end{array}$ & $\begin{array}{r}-0.0007 \\
(0.003)\end{array}$ & $\begin{array}{l}-0.039^{*} \\
(0.018)\end{array}$ & $\begin{array}{c}0.090 \\
(0.060)\end{array}$ & $\begin{array}{c}0.105 \\
(0.117)\end{array}$ & $\begin{array}{l}0.008 \\
(0.007)\end{array}$ & $\begin{array}{l}-0.004 \\
(0.008)\end{array}$ & $\begin{array}{l}-0.002 \\
(0.002)\end{array}$ & $\begin{array}{l}-0.039^{*} \\
(0.018)\end{array}$ & $\begin{array}{c}0.092 \\
(0.062)\end{array}$ \\
\hline IV Estimates & $\begin{array}{c}0.314 \\
(0.487)\end{array}$ & $\begin{array}{l}-0.155^{*} \\
(0.079)\end{array}$ & $\begin{array}{l}0.095^{*} \\
(0.047)\end{array}$ & $\begin{array}{c}0.016 \\
(0.027)\end{array}$ & $\begin{array}{l}-0.045 \\
(0.033)\end{array}$ & $\begin{array}{c}0.147 \\
(0.117)\end{array}$ & $\begin{array}{l}1.084^{*} \\
(0.564)\end{array}$ & $\begin{array}{l}-0.050 \\
(0.042)\end{array}$ & $\begin{array}{c}0.051 \\
(0.037)\end{array}$ & $\begin{array}{l}-0.0003 \\
(0.010)\end{array}$ & $\begin{array}{l}-0.029 \\
(0.024)\end{array}$ & $\begin{array}{c}0.077 \\
(0.083)\end{array}$ \\
\hline $\begin{array}{l}\text { Log Grams Hydrocodone } \\
\text { \& Oxycodone }\end{array}$ & & & & & & & & & & & & \\
\hline OLS Estimates & $\begin{array}{c}0.142 \\
(0.118)\end{array}$ & $\begin{array}{c}-0.024+ \\
(0.014)\end{array}$ & $\begin{array}{c}0.015 \\
(0.012)\end{array}$ & $\begin{array}{c}0.007 \\
(0.006)\end{array}$ & $\begin{array}{c}-0.025+ \\
(0.014)\end{array}$ & $\begin{array}{c}0.067 \\
(0.042)\end{array}$ & $\begin{array}{c}0.202 \\
(0.155)\end{array}$ & $\begin{array}{l}-0.011 \\
(0.008)\end{array}$ & $\begin{array}{c}0.010 \\
(0.012)\end{array}$ & $\begin{array}{l}0.0007 \\
(0.003)\end{array}$ & $\begin{array}{c}-0.024+ \\
(0.014)\end{array}$ & $\begin{array}{c}0.069 \\
(0.050)\end{array}$ \\
\hline IV Estimates & $\begin{array}{c}0.302 \\
(0.302)\end{array}$ & $\begin{array}{c}-0.102 * * \\
(0.040)\end{array}$ & $\begin{array}{c}0.054 * * \\
(0.021)\end{array}$ & $\begin{array}{l}0.0125 \\
(0.016)\end{array}$ & $\begin{array}{c}0.010 \\
(0.024)\end{array}$ & $\begin{array}{l}-0.024 \\
(0.053)\end{array}$ & $\begin{array}{l}0.717 * \\
(0.338)\end{array}$ & $\begin{array}{l}-0.033 \\
(0.025)\end{array}$ & $\begin{array}{c}0.028 \\
(0.020)\end{array}$ & $\begin{array}{c}0.001 \\
(0.006)\end{array}$ & $\begin{array}{c}0.008 \\
(0.024)\end{array}$ & $\begin{array}{l}-0.035 \\
(0.058)\end{array}$ \\
\hline $\begin{array}{l}\text { Demographic*Year } \\
\text { Controls }\end{array}$ & Yes & Yes & Yes & Yes & Yes & Yes & Yes & Yes & Yes & Yes & Yes & Yes \\
\hline $\begin{array}{l}\text { Mean of Dep. Var. } 2003 \\
\text { Standard Deviation }\end{array}$ & $\begin{array}{l}10.9 \\
(2.8)\end{array}$ & 0.77 & 0.15 & 0.10 & 0.22 & 0.34 & $\begin{array}{l}11.4 \\
(2.9)\end{array}$ & 0.77 & 0.15 & 0.06 & 0.25 & 0.29 \\
\hline Number of Observations & 678575 & 664854 & 664854 & 609240 & 692357 & 692357 & 1769109 & 1732664 & 1732664 & 1582224 & 1808372 & 1808372 \\
\hline
\end{tabular}

Notes: The unit of observation is the year-month-state-demographic cell. Demographic cells are defined based on race/ethnicity (white, black, Hispanic, other/unknown), education (less than high school, high school, some college, college or more, unknown education or education not reported in the state year), age (18-44 individual categories), and marital status (married/unmarried) in a given year. All regressions include controls for average plurality (order of birth) in the month-year-state-cell, share of male infant in the monthyear-state-cell, year of birth fixed effects, month of birth fixed effects and state of residence fixed effects, 18 months state unemployment levels $(9$ months of gestation and 9 months prior to gestation), annual state Medicaid thresholds for pregnant women, and annual state level share of individuals across all ages in poverty. All estimates also include the interaction between year dummy variables and mother's age, marital status and education with birth year, 18 months state unemployment levels ( 9 months of gestation and 9 months prior to gestation), annual state Medicaid thresholds for pregnant women, and annual state level share of individuals across all ages in poverty. Standard errors are constructed allowing for non-independence with state (cluster on state) ${ }^{+}$indicates $\mathrm{p}$-value $<=0.1, *$ indicates $0.01<\mathrm{p}$-value $<=0.05, * *$ indicates $\mathrm{p}$-value $<=0.01$ 
Table 11. Reduced Form Estimates of Effects of PDMPs and Pill Mill Laws on Birthweight, Low-birthweight (<2500 g.), Gestational Weeks, and C-Section, $2003-2016$ Sample of Unmarried Mothers

\begin{tabular}{|c|c|c|c|c|c|c|c|c|}
\hline & \multicolumn{4}{|c|}{ Ages 18 to 25} & \multicolumn{4}{|c|}{ Ages 26 to 44} \\
\hline & Birthweight & LBW & $\begin{array}{l}\text { Gestational } \\
\text { Weeks }\end{array}$ & C-Section & Birthweight & LBW & $\begin{array}{c}\text { Gestational } \\
\text { Weeks }\end{array}$ & C-Section \\
\hline Electronic PDMP & $\begin{array}{l}-0.017 \\
(1.74)\end{array}$ & $\begin{array}{c}0.0005 \\
(0.0006)\end{array}$ & $\begin{array}{l}-0.004 \\
(0.012)\end{array}$ & $\begin{array}{c}0.001 \\
(0.002)\end{array}$ & $\begin{array}{c}-0.002 \\
(1.920)\end{array}$ & $\begin{array}{l}-0.0003 \\
(0.0005)\end{array}$ & $\begin{array}{c}0.008 \\
(0.013)\end{array}$ & $\begin{array}{l}-0.0004 \\
(0.0025)\end{array}$ \\
\hline Modern PDMP & $\begin{array}{c}0.570 \\
(2.370)\end{array}$ & $\begin{array}{l}-0.0001 \\
(0.0009)\end{array}$ & $\begin{array}{c}0.011 \\
(0.012)\end{array}$ & $\begin{array}{c}-0.001 \\
(0.0022)\end{array}$ & $\begin{array}{c}0.528 \\
(2.931)\end{array}$ & $\begin{array}{l}-0.0007 \\
(0.001)\end{array}$ & $\begin{array}{c}0.025 \\
(0.017)\end{array}$ & $\begin{array}{c}-0.004+ \\
(0.002)\end{array}$ \\
\hline Pill Mill & $\begin{array}{c}4.630 * * \\
(1.480)\end{array}$ & $\begin{array}{r}-0.0011+ \\
(0.0006)\end{array}$ & $\begin{array}{l}-0.011 \\
(0.013)\end{array}$ & $\begin{array}{l}0.004+ \\
(0.002)\end{array}$ & $\begin{array}{l}4.804 * \\
(1.878)\end{array}$ & $\begin{array}{c}0.0001 \\
(0.0008)\end{array}$ & $\begin{array}{l}-0.017 \\
(0.014)\end{array}$ & $\begin{array}{c}0.003 \\
(0.002)\end{array}$ \\
\hline $\begin{array}{l}\text { Demographic*Year Controls } \\
\text { Mean of Dep. Var. in } 2003 \\
\text { Standard Dev. for Cont. Outcomes } \\
\text { Number of Observations }\end{array}$ & $\begin{array}{c}\text { Yes } \\
3140 \\
(512) \\
855,409\end{array}$ & $\begin{array}{c}\text { Yes } \\
0.116 \\
855,409\end{array}$ & $\begin{array}{c}\text { Yes } \\
38.2 \\
(2.86) \\
855,409\end{array}$ & $\begin{array}{c}\text { Yes } \\
0.24 \\
855,409\end{array}$ & $\begin{array}{c}\text { Yes } \\
3161 \\
(574) \\
1379725\end{array}$ & $\begin{array}{c}\text { Yes } \\
0.13 \\
1379725\end{array}$ & $\begin{array}{c}\text { Yes } \\
38.2 \\
(2.80) \\
1379725\end{array}$ & $\begin{array}{c}\text { Yes } \\
0.36 \\
1379725\end{array}$ \\
\hline
\end{tabular}

Notes : The unit of observation is the year-month-state-demographic cell. Demographic cells are defined based on race/ethnicity (white, black, Hispanic, other/unknown),

education (less than high school, high school, some college, college or more, unknown education or education not reported in the state year), age (18-44 individual categories), and marital status (married/unmarried) in a given year. All regressions include controls for average plurality (order of birth) in the month-year-state-cell, share of male infant in the month- year-state-cell, year of birth fixed effects, month of birth fixed effects and state of residence fixed effects, 18 months state unemployment levels (9 months of gestation and 9 months prior to gestation), annual state Medicaid thresholds for pregnant women, and annual state level share of individuals across all ages in poverty. All estimates also include the interaction between year dummy variables and mother's age, marital status and education with birth year, 18 months state unemployment levels ( 9 months of gestation and 9 months prior to gestation), annual state Medicaid thresholds for pregnant women, and annual state level share of individuals across all ages in poverty. Standard errors are constructed allowing for non-independence with state (cluster on state). ${ }^{+}$indicates p-value $<=0.1, *$ indicates $0.01<$ p-value $<=0.05, * *$ indicates $\mathrm{p}$-value $<=0.01$ 
Table 12. Reduced Form Estimates of Effects of PDMPs and Pill Mill Laws on Birthweight, Low-birthweight (<2500 g.), Gestational Weeks, and C-Section, $2003-2016$ Sample of Married Mothers

\begin{tabular}{|c|c|c|c|c|c|c|c|c|}
\hline & \multicolumn{4}{|c|}{ Ages 18 to 25} & \multicolumn{4}{|c|}{ Ages 26 to 44} \\
\hline & Birthweight & LBW & $\begin{array}{c}\text { Gestational } \\
\text { Weeks }\end{array}$ & C-Section & Birthweight & LBW & $\begin{array}{c}\text { Gestational } \\
\text { Weeks }\end{array}$ & C-Section \\
\hline Electronic PDMP & $\begin{array}{c}1.470 \\
(1.690)\end{array}$ & $\begin{array}{c}-0.0004 \\
(0.0004)\end{array}$ & $\begin{array}{c}0.007 \\
(0.015)\end{array}$ & $\begin{array}{c}-0.000002 \\
(0.002)\end{array}$ & $\begin{array}{l}1.057 \\
(1.53)\end{array}$ & $\begin{array}{c}-0.00004 \\
(0.0004)\end{array}$ & $\begin{array}{c}0.008 \\
(0.012)\end{array}$ & $\begin{array}{c}-0.003 \\
(0.002)\end{array}$ \\
\hline Modern PDMP & $\begin{array}{c}2.420 \\
(1.860)\end{array}$ & $\begin{array}{l}-0.0009 \\
(0.0007)\end{array}$ & $\begin{array}{c}0.020 \\
(0.016)\end{array}$ & $\begin{array}{c}-0.002 \\
(0.001)\end{array}$ & $\begin{array}{c}3.340^{+} \\
(1.840)\end{array}$ & $\begin{array}{l}-0.001^{+} \\
(0.0005)\end{array}$ & $\begin{array}{c}0.022 \\
(0.015)\end{array}$ & $\begin{array}{c}-0.006^{*} \\
(0.003)\end{array}$ \\
\hline Pill Mill & $\begin{array}{l}4.750^{*} \\
(2.230)\end{array}$ & $\begin{array}{l}-0.001 \\
(0.001)\end{array}$ & $\begin{array}{l}0.0007 \\
(0.017)\end{array}$ & $\begin{array}{c}0.003 \\
(0.003)\end{array}$ & $\begin{array}{l}4.380^{*} \\
(1.680)\end{array}$ & $\begin{array}{r}-0.00002 \\
(0.0004)\end{array}$ & $\begin{array}{l}-0.009 \\
(0.013)\end{array}$ & $\begin{array}{l}0.0013 \\
(0.003)\end{array}$ \\
\hline $\begin{array}{l}\text { Demographic*Year Controls } \\
\text { Mean of Dep. Var. in } 2003 \\
\text { Standard Dev. for Cont. Outcomes } \\
\text { Number of Observations }\end{array}$ & $\begin{array}{c}\text { Yes } \\
3220 \\
(465) \\
691350\end{array}$ & $\begin{array}{c}\text { Yes } \\
0.089 \\
691350\end{array}$ & $\begin{array}{c}\text { Yes } \\
38.6 \\
(2.4) \\
691350\end{array}$ & $\begin{array}{c}\text { Yes } \\
0.238 \\
691350\end{array}$ & $\begin{array}{c}\text { Yes } \\
3266 \\
(598) \\
1805652\end{array}$ & $\begin{array}{c}\text { Yes } \\
0.102 \\
1805652\end{array}$ & $\begin{array}{c}\text { Yes } \\
38.7 \\
(5.0) \\
1805652\end{array}$ & $\begin{array}{c}\text { Yes } \\
0.365 \\
1805652\end{array}$ \\
\hline
\end{tabular}

Notes: The unit of observation is the year-month-state-demographic cell. Demographic cells are defined based on race/ethnicity (white, black, Hispanic, other/unknown), education (less than high school, high school, some college, college or more, unknown education or education not reported in the state year), age (18-44 individual categories), and marital status (married/unmarried) in a given year. All regressions include controls for average plurality (order of birth) in the month-year-state-cell, share of male infant in the monthyear-state-cell, year of birth fixed effects, month of birth fixed effects and state of residence fixed effects, 18 months state unemployment levels $(9$ months of gestation and 9 months prior to gestation), annual state Medicaid thresholds for pregnant women, and annual state level share of individuals across all ages in poverty. All estimates also include the interaction between year dummy variables and mother's age, marital status and education with birth year, 18 months state unemployment levels ( 9 months of gestation and 9 months prior to gestation), annual state Medicaid thresholds for pregnant women, and annual state level share of individuals across all ages in poverty. Standard errors are constructed allowing for non-independence with state (cluster on state). ${ }^{+}$indicates p-value $<=0.1, *$ indicates $0.01<$ p-value $<=0.05$, $* *$ indicates -value $<=0.01$ 
Table 13. Reduced Form Estimates of Effects of PDMPs and Pill Mill Laws on Prenatal Visits, Smoking during Pregnancy, and Weight Gain Sample of Unmarried Mothers

\begin{tabular}{|c|c|c|c|c|c|c|c|c|c|c|c|c|}
\hline & \multicolumn{6}{|c|}{ Ages 18 to 25} & \multicolumn{6}{|c|}{ Ages 26 to 44} \\
\hline & $\begin{array}{c}\text { Number } \\
\text { Prenatal } \\
\text { Visits } \\
\end{array}$ & $\begin{array}{l}\text { First } \\
\text { Trim. } \\
\text { Visit }\end{array}$ & $\begin{array}{c}\text { Inadeq. } \\
\text { Prenatal } \\
\text { Care } \\
\end{array}$ & $\begin{array}{c}\text { Smoked } \\
\text { During } \\
\text { Preg. }\end{array}$ & $\begin{array}{c}\text { Weight } \\
\text { Gain }<20 \\
\text { lbs. }\end{array}$ & $\begin{array}{c}\text { Weight } \\
\text { gain }>40 \\
\text { lbs. }\end{array}$ & $\begin{array}{c}\text { Number } \\
\text { Prenatal } \\
\text { Visits } \\
\end{array}$ & $\begin{array}{l}\text { First } \\
\text { Trim. } \\
\text { Visit }\end{array}$ & $\begin{array}{c}\text { Inadeq. } \\
\text { Prenatal } \\
\text { Care }\end{array}$ & $\begin{array}{c}\text { Smoked } \\
\text { During } \\
\text { Preg. }\end{array}$ & $\begin{array}{c}\text { Weight } \\
\text { Gain }<20 \\
\text { lbs. }\end{array}$ & $\begin{array}{c}\text { Weight } \\
\text { gain }>40 \\
\text { lbs. }\end{array}$ \\
\hline Electronic PDMP & $\begin{array}{c}0.082 \\
(0.079)\end{array}$ & $\begin{array}{l}0.0031 \\
(0.014)\end{array}$ & $\begin{array}{l}-0.011 \\
(0.015)\end{array}$ & $\begin{array}{c}0.003 \\
(0.005)\end{array}$ & $\begin{array}{l}0.022+ \\
(0.013)\end{array}$ & $\begin{array}{l}-0.064 \\
(0.045)\end{array}$ & $\begin{array}{c}0.114 \\
(0.0840)\end{array}$ & $\begin{array}{c}0.004 \\
(0.012)\end{array}$ & $\begin{array}{l}-0.012 \\
(0.015)\end{array}$ & $\begin{array}{c}0.005 \\
(0.005)\end{array}$ & $\begin{array}{l}0.027+ \\
(0.016)\end{array}$ & $\begin{array}{l}-0.065 \\
(0.047)\end{array}$ \\
\hline Modern PDMP & $\begin{array}{l}-0.110 \\
(0.140)\end{array}$ & $\begin{array}{c}0.001 \\
(0.020)\end{array}$ & $\begin{array}{l}-0.008 \\
(0.020)\end{array}$ & $\begin{array}{c}0.001 \\
(0.008)\end{array}$ & $\begin{array}{c}0.027 \\
(0.018)\end{array}$ & $\begin{array}{l}-0.081 \\
(0.054)\end{array}$ & $\begin{array}{l}-0.110 \\
(0.138)\end{array}$ & $\begin{array}{c}0.007 \\
(0.016)\end{array}$ & $\begin{array}{l}-0.01 \\
(0.02)\end{array}$ & $\begin{array}{r}-0.0003 \\
(0.007)\end{array}$ & $\begin{array}{l}0.037+ \\
(0.022)\end{array}$ & $\begin{array}{l}-0.093 \\
(0.058)\end{array}$ \\
\hline Pill Mill & $\begin{array}{c}0.147 \\
(0.106)\end{array}$ & $\begin{array}{c}0.064 * * \\
(0.017)\end{array}$ & $\begin{array}{c}-0.034 * * \\
(0.009)\end{array}$ & $\begin{array}{l}-0.008 \\
(0.006)\end{array}$ & $\begin{array}{l}-0.002 \\
(0.010)\end{array}$ & $\begin{array}{c}0.017 \\
(0.023)\end{array}$ & $\begin{array}{l}0.0321 \\
(0.137)\end{array}$ & $\begin{array}{c}0.050 * * \\
(0.014)\end{array}$ & $\begin{array}{c}-0.030 * * \\
(0.01)\end{array}$ & $\begin{array}{l}-0.004 \\
(0.005)\end{array}$ & $\begin{array}{l}-0.008 \\
(0.014)\end{array}$ & $\begin{array}{c}0.027 \\
(0.029)\end{array}$ \\
\hline Demographic*Year Controls & Yes & Yes & Yes & Yes & Yes & Yes & Yes & Yes & Yes & Yes & Yes & Yes \\
\hline $\begin{array}{l}\text { Mean of Dep. Var. in } 2003 \\
\text { Standard Deviation }\end{array}$ & $\begin{array}{l}10.2 \\
(3.0)\end{array}$ & 0.77 & 0.15 & 0.19 & 0.22 & 0.36 & $\begin{array}{l}10.5 \\
(3.6)\end{array}$ & 0.77 & 0.15 & 0.21 & 0.27 & 0.33 \\
\hline Number of Observations & 838578 & 822170 & 822170 & 767393 & 856496 & 856496 & 1344255 & 1318561 & 1318561 & 1213416 & 1381638 & 1381638 \\
\hline
\end{tabular}

Notes: The unit of observation is the year-month-state-demographic cell. Demographic cells are defined based on race/ethnicity (white, black, Hispanic, other/unknown), education (less than high school, high school, some college, college or more, unknown education or education not reported in the state year), age (18-44 individual categories), and marital status (married/unmarried) in a given year. All regressions include controls for average plurality (order of birth) in the month-year-state-cell, share of male infant in the monthyear-state-cell, year of birth fixed effects, month of birth fixed effects and state of residence fixed effects, 18 months state unemployment levels $(9$ months of gestation and 9 months prior to gestation), annual state Medicaid thresholds for pregnant women, and annual state level share of individuals across all ages in poverty. All estimates also include the interaction between year dummy variables and mother's age, marital status and education with birth year, 18 months state unemployment levels ( 9 months of gestation and 9 months prior to gestation), annual state Medicaid thresholds for pregnant women, and annual state level share of individuals across all ages in poverty. Standard errors are constructed allowing for non-independence with state (cluster on state). ${ }^{+}$indicates p-value $<=0.1, *$ indicates $0.01<\mathrm{p}$-value $<=0.05, * *$ indicates $\mathrm{p}$-value $<=0.01$ 
Table 14. Reduced Form Estimates of Effects of PDMPs and Pill Mill Laws on Prenatal Visits, Smoking during Pregnancy, and Weight Gain Sample of Married Mothers

\begin{tabular}{|c|c|c|c|c|c|c|c|c|c|c|c|c|}
\hline & \multicolumn{6}{|c|}{ Ages 18 to 25} & \multicolumn{6}{|c|}{ Ages 26 to 44} \\
\hline & $\begin{array}{c}\text { Number } \\
\text { Prenatal } \\
\text { Visits } \\
\end{array}$ & $\begin{array}{l}\text { First } \\
\text { Trim. } \\
\text { Visit }\end{array}$ & $\begin{array}{l}\text { Inadeq. } \\
\text { Prenatal } \\
\text { Care } \\
\end{array}$ & $\begin{array}{c}\text { Smoked } \\
\text { During } \\
\text { Preg. }\end{array}$ & $\begin{array}{c}\text { Weight } \\
\text { Gain }<20 \\
\text { lbs. }\end{array}$ & $\begin{array}{c}\text { Weight } \\
\text { gain }>40 \\
\text { lbs. }\end{array}$ & $\begin{array}{c}\text { Number } \\
\text { Prenatal } \\
\text { Visits } \\
\end{array}$ & $\begin{array}{l}\text { First } \\
\text { Trim. } \\
\text { Visit } \\
\end{array}$ & $\begin{array}{l}\text { Inadeq. } \\
\text { Prenatal } \\
\text { Care } \\
\end{array}$ & $\begin{array}{c}\text { Smoked } \\
\text { During } \\
\text { Preg. }\end{array}$ & $\begin{array}{c}\text { Weight } \\
\text { Gain }<20 \\
\text { lbs. }\end{array}$ & $\begin{array}{l}\text { Weight } \\
\text { gain }>40 \\
\text { lbs. }\end{array}$ \\
\hline Electronic PDMP & $\begin{array}{c}0.090 \\
(0.089)\end{array}$ & $\begin{array}{l}0.0019 \\
(0.012)\end{array}$ & $\begin{array}{c}-0.004 \\
(0.012)\end{array}$ & $\begin{array}{c}0.003 \\
(0.003)\end{array}$ & $\begin{array}{l}0.026+ \\
(0.015)\end{array}$ & $\begin{array}{l}-0.080 \\
(0.053)\end{array}$ & $\begin{array}{c}0.081 \\
(0.089)\end{array}$ & $\begin{array}{c}0.003 \\
(0.009)\end{array}$ & $\begin{array}{l}-0.008 \\
(0.012)\end{array}$ & $\begin{array}{c}0.002 \\
(0.002)\end{array}$ & $\begin{array}{l}0.027+ \\
(0.015)\end{array}$ & $\begin{array}{c}-0.082 \\
(0.059)\end{array}$ \\
\hline Modern PDMP & $\begin{array}{l}-0.101 \\
(0.133)\end{array}$ & $\begin{array}{l}0.0033 \\
(0.016)\end{array}$ & $\begin{array}{l}-0.010 \\
(0.015)\end{array}$ & $\begin{array}{c}0.005 \\
(0.005)\end{array}$ & $\begin{array}{l}0.034+ \\
(0.019)\end{array}$ & $\begin{array}{l}-0.103 \\
(0.063)\end{array}$ & $\begin{array}{l}-0.201 \\
(0.147)\end{array}$ & $\begin{array}{l}0.0004 \\
(0.010)\end{array}$ & $\begin{array}{l}-0.009 \\
(0.015)\end{array}$ & $\begin{array}{c}0.002 \\
(0.003)\end{array}$ & $\begin{array}{l}0.034+ \\
(0.019)\end{array}$ & $\begin{array}{l}-0.109 \\
(0.069)\end{array}$ \\
\hline Pill Mill & $\begin{array}{l}-0.015 \\
(0.107)\end{array}$ & $\begin{array}{c}0.040 * * \\
(0.013)\end{array}$ & $\begin{array}{c}-0.019 * * \\
(0.007)\end{array}$ & $\begin{array}{l}-0.005 \\
(0.005)\end{array}$ & $\begin{array}{l}-0.009 \\
(0.011)\end{array}$ & $\begin{array}{c}0.024 \\
(0.027)\end{array}$ & $\begin{array}{l}-0.139 \\
(0.127)\end{array}$ & $\begin{array}{c}0.016 \\
(0.011)\end{array}$ & $\begin{array}{l}-0.009 \\
(0.007)\end{array}$ & $\begin{array}{l}-0.0006 \\
(0.002)\end{array}$ & $\begin{array}{c}-0.011 \\
(0.012)\end{array}$ & $\begin{array}{c}0.041 \\
(0.036)\end{array}$ \\
\hline $\begin{array}{l}\text { Demographic*Year Controls } \\
\text { Mean of Dep. Var. in } 2003 \\
\text { Standard Deviation } \\
\text { Number of Observations }\end{array}$ & $\begin{array}{l}\text { Yes } \\
10.9 \\
(2.8) \\
678575\end{array}$ & $\begin{array}{c}\text { Yes } \\
0.77 \\
664854\end{array}$ & $\begin{array}{c}\text { Yes } \\
0.15 \\
664854\end{array}$ & $\begin{array}{c}\text { Yes } \\
0.10 \\
609240\end{array}$ & $\begin{array}{c}\text { Yes } \\
0.22 \\
692357\end{array}$ & $\begin{array}{c}\text { Yes } \\
0.34 \\
692357\end{array}$ & $\begin{array}{c}\text { Yes } \\
11.4 \\
(2.9) \\
1769109\end{array}$ & $\begin{array}{l}\text { Yes } \\
0.77\end{array}$ & $\begin{array}{l}\text { Yes } \\
0.15\end{array}$ & $\begin{array}{c}\text { Yes } \\
0.06\end{array}$ & $\begin{array}{l}\text { Yes } \\
0.25\end{array}$ & $\begin{array}{c}\text { Yes } \\
0.29\end{array}$ \\
\hline
\end{tabular}

Notes: The unit of observation is the year-month-state-demographic cell. Demographic cells are defined based on race/ethnicity (white, black, Hispanic, other/unknown), education (less than high school, high school, some college, college or more, unknown education or education not reported in the state year), age (18-44 individual categories), and marital status (married/unmarried) in a given year. All regressions include controls for average plurality (order of birth) in the month-year-state-cell, share of male infant in the monthyear-state-cell, year of birth fixed effects, month of birth fixed effects and state of residence fixed effects, 18 months state unemployment levels $(9$ months of gestation and 9 months prior to gestation), annual state Medicaid thresholds for pregnant women, and annual state level share of individuals across all ages in poverty. All estimates also include the interaction between year dummy variables and mother's age, marital status and education with birth year, 18 months state unemployment levels ( 9 months of gestation and 9 months prior to gestation), annual state Medicaid thresholds for pregnant women, and annual state level share of individuals across all ages in poverty. Standard errors are constructed allowing for non-independence with state (cluster on state) ${ }^{+}$indicates p-value $<=0.1, *$ indicates $0.01<\mathrm{p}$-value $<=0.05, * *$ indicates $\mathrm{p}$-value $<=0.01$ 
Appendix Table 1. OLS and Instrumental Variables (IV) Estimates of Effects of (Per-100 capita) Prescription Opioids on Birthweight, Low-birthweight ( $<2500$ g.), Gestational Weeks, and C-Section

\begin{tabular}{|c|c|c|c|c|c|c|c|c|}
\hline Per-100 capita Grams All Opioids & \multicolumn{2}{|c|}{ Birthweight } & \multicolumn{2}{|c|}{ Low Birthweight (LBW) } & \multicolumn{2}{|c|}{ Gestational Weeks } & \multicolumn{2}{|c|}{ C-Section } \\
\hline OLS Estimates & $\begin{array}{c}0.306 \\
(0.284)\end{array}$ & $\begin{array}{l}-0.108 \\
(0.199)\end{array}$ & $\begin{array}{c}-6.36 \mathrm{E}-05 \\
(0.00006)\end{array}$ & $\begin{array}{c}2.64 \mathrm{E}-06 \\
(0.0001)\end{array}$ & $\begin{array}{c}0.001 \\
(0.002)\end{array}$ & $\begin{array}{r}-0.0007 \\
(0.002)\end{array}$ & $\begin{array}{l}-0.0002 \\
(0.0002)\end{array}$ & $\begin{array}{r}-4.6 \mathrm{E}-05 \\
(0.0002)\end{array}$ \\
\hline IV Estimates & $\begin{array}{l}-2.604 * \\
(1.111)\end{array}$ & $\begin{array}{c}-2.688 * * \\
(1.061)\end{array}$ & $\begin{array}{c}0.0002 \\
(0.0002)\end{array}$ & $\begin{array}{c}0.001 \\
(0.0004)\end{array}$ & $\begin{array}{l}-0.001 \\
(0.004)\end{array}$ & $\begin{array}{l}-0.003 \\
(0.005)\end{array}$ & $\begin{array}{r}-0.0005 \\
(0.001)\end{array}$ & $\begin{array}{l}-0.001 \\
(0.001)\end{array}$ \\
\hline Per-100 capita Grams Hydro. \& Ox & & & & & & & & \\
\hline OLS Estimates & $\begin{array}{l}-0.098 \\
(0.349)\end{array}$ & $\begin{array}{l}-0.295 \\
(0.321)\end{array}$ & $\begin{array}{c}-8.83 \mathrm{E}-05 \\
(0.0001)\end{array}$ & $\begin{array}{l}-2.2 \mathrm{E}-05 \\
(0.0001)\end{array}$ & $\begin{array}{l}-0.002 \\
(0.002)\end{array}$ & $\begin{array}{l}-0.003 * \\
(0.002)\end{array}$ & $\begin{array}{c}0.0002 \\
(0.0003)\end{array}$ & $\begin{array}{c}0.0003 \\
(0.0002)\end{array}$ \\
\hline IV Estimates & $\begin{array}{l}-2.712 * \\
(1.259)\end{array}$ & $\begin{array}{c}-2.640 * * \\
(1.054)\end{array}$ & $\begin{array}{l}0.0001 \\
(0.000)\end{array}$ & $\begin{array}{c}0.0005 \\
(0.0004)\end{array}$ & $\begin{array}{l}0.0004 \\
(0.005)\end{array}$ & $\begin{array}{c}0.001 \\
(0.005)\end{array}$ & $\begin{array}{c}-0.001 \\
(0.001)\end{array}$ & $\begin{array}{l}0.0001 \\
(0.001)\end{array}$ \\
\hline $\begin{array}{l}\text { Demographic*Year Controls } \\
\text { Mean of Dep. Var. in } 2003 \\
\text { Standard Dev. for Cont. Outcomes } \\
\text { Number of Observations }\end{array}$ & $\begin{array}{c}\text { No } \\
3220.9 \\
(605) \\
4732136\end{array}$ & $\begin{array}{c}\text { Yes } \\
3220.9 \\
(605) \\
4732136\end{array}$ & $\begin{array}{c}\text { No } \\
0.111 \\
4732136\end{array}$ & $\begin{array}{c}\text { Yes } \\
0.111 \\
4732136\end{array}$ & $\begin{array}{c}\text { No } \\
0.329 \\
4732136\end{array}$ & $\begin{array}{c}\text { Yes } \\
0.329 \\
4732136\end{array}$ & $\begin{array}{c}\text { No } \\
0.329 \\
4732136\end{array}$ & $\begin{array}{c}\text { Yes } \\
0.329 \\
4732136\end{array}$ \\
\hline
\end{tabular}

Notes: The unit of observation is the year-month-state-demographic cell. Demographic cells are defined based on race/ethnicity (white, black, Hispanic, other/unknown), education (less than high school, high school, some college, college or more, unknown education or education not reported in the state year), age (18-44 individual categories), and marital status (married/unmarried) in a given year. All regressions include controls for average plurality (order of birth) in the month-year-state-cell, share of male infant in the monthyear-state-cell, year of birth fixed effects, month of birth fixed effects and state of residence fixed effects, 18 months state unemployment levels (9 months of gestation and 9 months prior to gestation), annual state Medicaid thresholds for pregnant women, and annual state level share of individuals across all ages in poverty. Estimates in second column for each dependent variable add additional controls: the interaction between year dummy variables and mother's age, marital status and education with birth year, 18 months state unemployment levels ( 9 months of gestation and 9 months prior to gestation), annual state Medicaid thresholds for pregnant women, and annual state level share of individuals across all ages in poverty. Standard errors are constructed allowing for non-independence with state (cluster on state). ${ }^{+}$indicates $\mathrm{p}$-value $<=0.1,{ }^{*}$ indicates $0.01<\mathrm{p}$-value $<=0.05$, $* *$ indicates $p$-value $<=0.01$ 
Appendix Table 2. OLS and Instrumental Variables (IV) Estimates of Effects of (Per Capita) Prescription Opioids on Prenatal Visits, Smoking during Pregnancy, and Weight Gain

\begin{tabular}{|c|c|c|c|c|c|c|}
\hline Per-capita Grams All Prescription Opioids & $\begin{array}{c}\text { Number Prenatal } \\
\text { Visits }\end{array}$ & $\begin{array}{c}\text { First Trimester } \\
\text { Visit }\end{array}$ & $\begin{array}{c}\text { Inadequate } \\
\text { Prenatal Care }\end{array}$ & $\begin{array}{c}\text { Smoked During } \\
\text { Pregnancy }\end{array}$ & $\begin{array}{c}\text { Weight Gain }<20 \\
\text { lbs. }\end{array}$ & $\begin{array}{c}\text { Weight gain }>40 \\
\text { lbs. }\end{array}$ \\
\hline OLS Estimates & $\begin{array}{l}0.027^{*} \\
(0.016)\end{array}$ & $\begin{array}{c}0.002 \\
(0.002)\end{array}$ & $\begin{array}{c}-0.003+ \\
(0.001)\end{array}$ & $\begin{array}{c}-0.0004 \\
(0.000)\end{array}$ & $\begin{array}{c}-0.003 * * \\
(0.001)\end{array}$ & $\begin{array}{c}0.006 \\
(0.005)\end{array}$ \\
\hline IV Estimates & $\begin{array}{c}0.106 \\
(0.072)\end{array}$ & $\begin{array}{c}-0.141^{+} \\
(0.008)\end{array}$ & $\begin{array}{c}0.010 \\
(0.006)\end{array}$ & $\begin{array}{c}0.002 \\
(0.002)\end{array}$ & $\begin{array}{c}-0.005+ \\
(0.003)\end{array}$ & $\begin{array}{l}0.0138 \\
(0.011)\end{array}$ \\
\hline \multicolumn{7}{|l|}{ Per-capita Grams Hydrocodone \& Oxycodone } \\
\hline OLS Estimates & $\begin{array}{l}0.053^{*} \\
(0.027)\end{array}$ & $\begin{array}{c}0.003 \\
(0.003)\end{array}$ & $\begin{array}{l}-0.004 \\
(0.002)\end{array}$ & $\begin{array}{c}-0.0002 \\
(0.001)\end{array}$ & $\begin{array}{l}-0.001 \\
(0.002)\end{array}$ & $\begin{array}{c}0.002 \\
(0.005)\end{array}$ \\
\hline IV Estimates & $\begin{array}{c}0.112 \\
(0.076)\end{array}$ & $\begin{array}{l}-0.154^{+} \\
(0.008)\end{array}$ & $\begin{array}{c}0.009^{+} \\
(0.005)\end{array}$ & $\begin{array}{c}0.003 \\
(0.002)\end{array}$ & $\begin{array}{l}-0.0005 \\
(0.004)\end{array}$ & $\begin{array}{l}0.0004 \\
(0.010)\end{array}$ \\
\hline $\begin{array}{l}\text { Demographic*Year Controls } \\
\text { Mean of Dep. Var. in } 2003 \\
\text { Standard Dev. for Cont. Outcomes } \\
\text { Number of Observations }\end{array}$ & $\begin{array}{c}\text { Yes } \\
10.9 \\
(3.23) \\
4630517\end{array}$ & $\begin{array}{c}\text { Yes } \\
0.77 \\
4538249\end{array}$ & $\begin{array}{c}\text { Yes } \\
0.15 \\
4538249\end{array}$ & $\begin{array}{c}\text { Yes } \\
0.13 \\
4172273\end{array}$ & $\begin{array}{c}\text { Yes } \\
0.25 \\
4738863\end{array}$ & $\begin{array}{c}\text { Yes } \\
0.32 \\
4738863\end{array}$ \\
\hline
\end{tabular}

Notes: The unit of observation is the year-month-state-demographic cell. Demographic cells are defined based on race/ethnicity (white, black, Hispanic, other/unknown), education

(less than high school, high school, some college, college or more, unknown education or education not reported in the state year), age (18-44 individual categories), and marital

status (married/unmarried) in a given year. All regressions include controls for average plurality (order of birth) in the month-year-state-cell, share of male infant in the month-

year-state-cell, year of birth fixed effects, month of birth fixed effects and state of residence fixed effects, 18 months state unemployment levels $(9$ months of gestation and 9

months prior to gestation), annual state Medicaid thresholds for pregnant women, and annual state level share of individuals across all ages in poverty. All estimates also include

the interaction between year dummy variables and mother's age, marital status and education with birth year, 18 months state unemployment levels (9 months of gestation and 9

months prior to gestation), annual state Medicaid thresholds for pregnant women, and annual state level share of individuals across all ages in poverty. Standard errors are

constructed allowing for non-independence with state (cluster on state). ${ }^{+}$indicates p-value $<=0.1, *$ indicates $0.01<\mathrm{p}$-value $<=0.05, * *$ indicates $\mathrm{p}$-value $<=0.01$ 
Figure 1 - Frequency of PDMP Policies Across all 51 States over Time

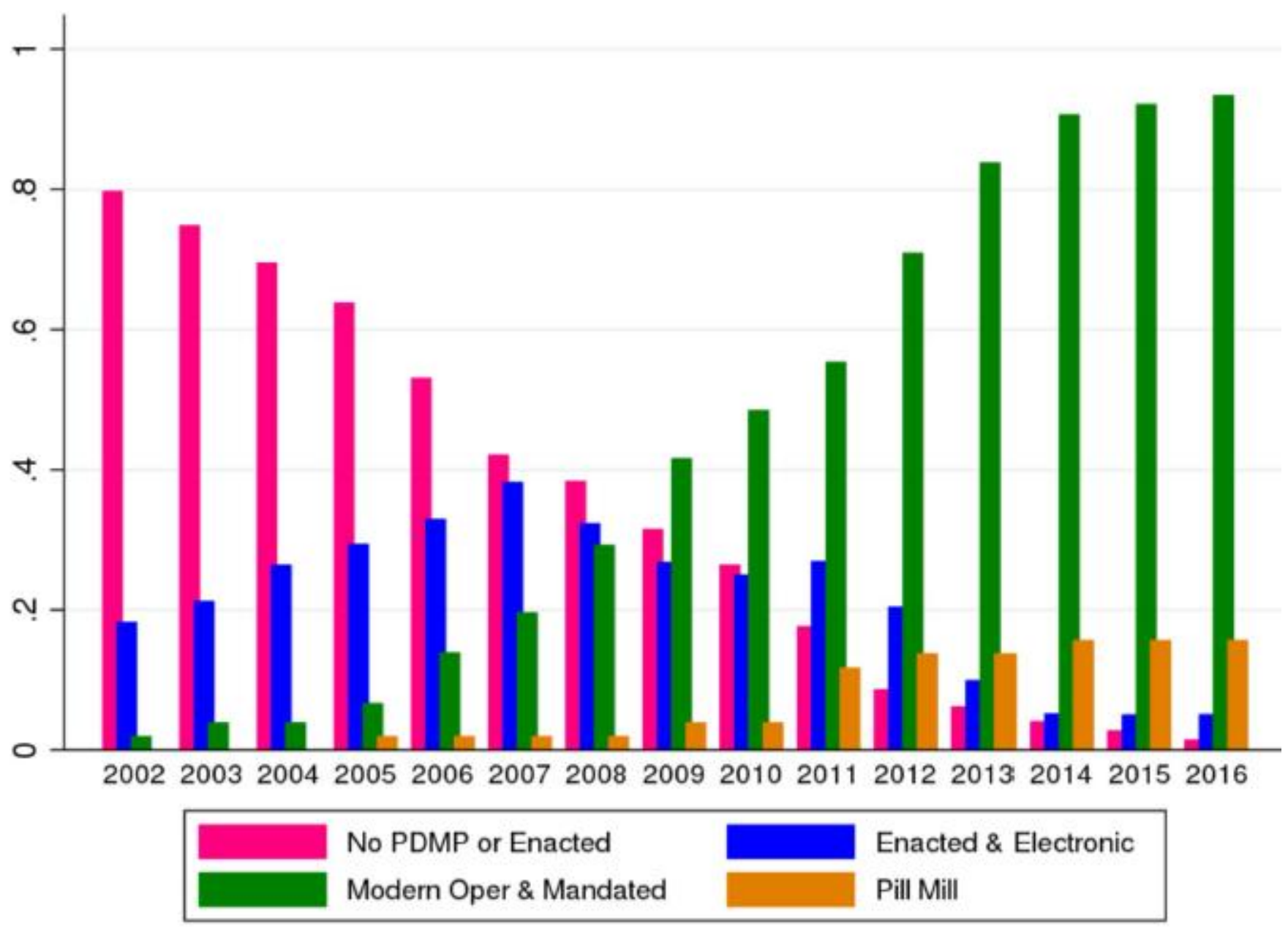


Figure 2: Event Study Coefficients of the Modern Prescription Drug Monitoring Programs on Log Total Grams and Per Capita Opioid Sales 2002-2016

A. All Opioids
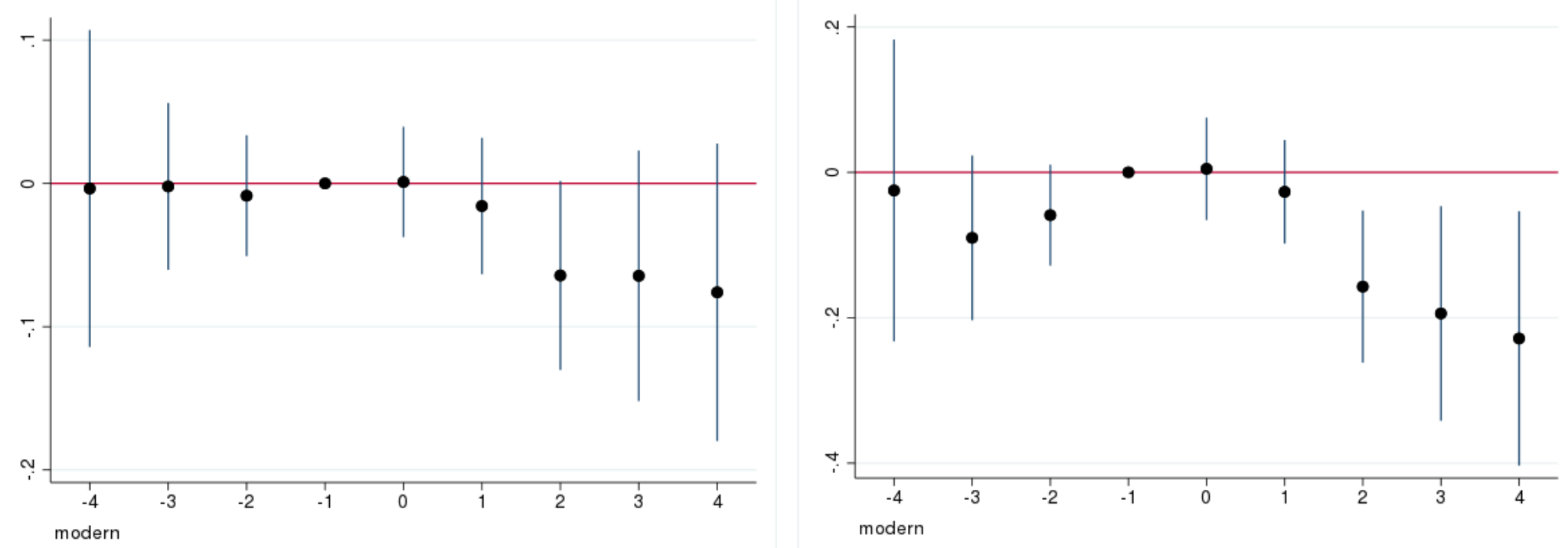

Log Total Grams

Per Capita Grams

B. Hydrocodone/ Oxycodone
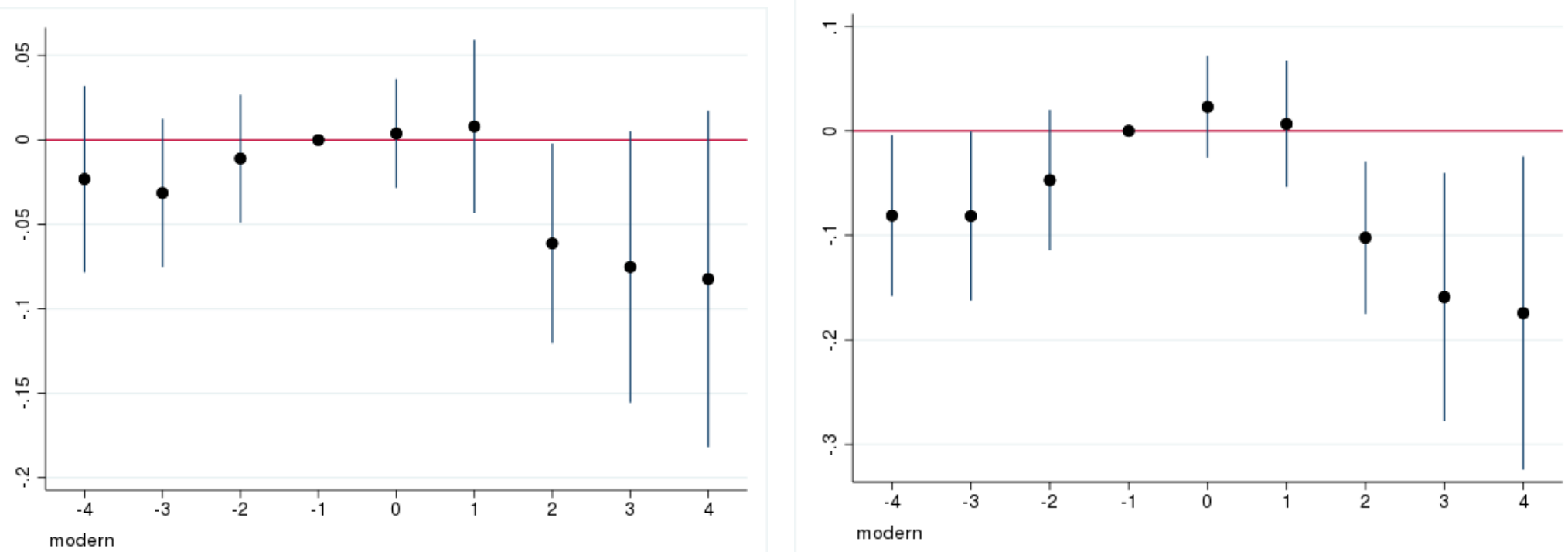

Log Total Grams

Per Capita Grams 
Figure 3: Event Study Coefficients of the Pill Mill Laws on Log Total Grams and Per Capita Opioid Sales 20022016

A. All Opioids
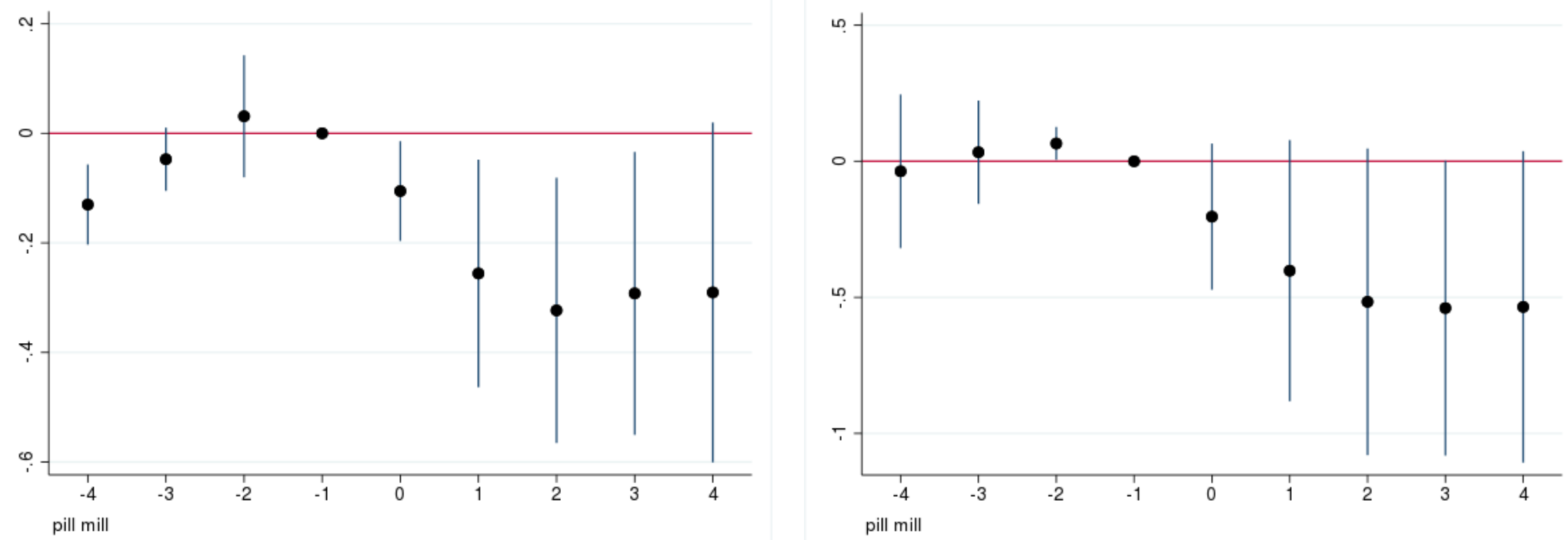

Log Total Grams

Per Capita Grams

B. Hydrocodone/Oxycodone
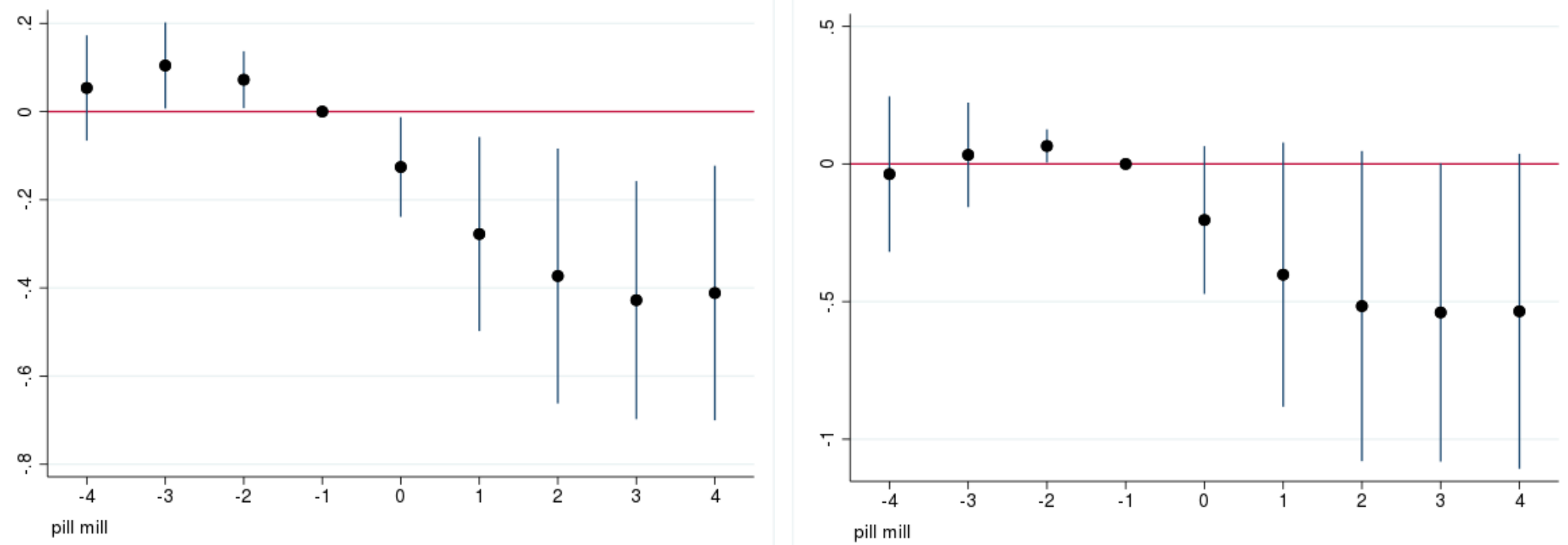

Log Total Grams

Per Capita Grams 
Figure 4: Event Study Coefficients of the Modern Prescription Drug Monitoring Program (PDMP) and Pill Mill Laws on Birth Weight 2002-2016

A. Modern PDMP

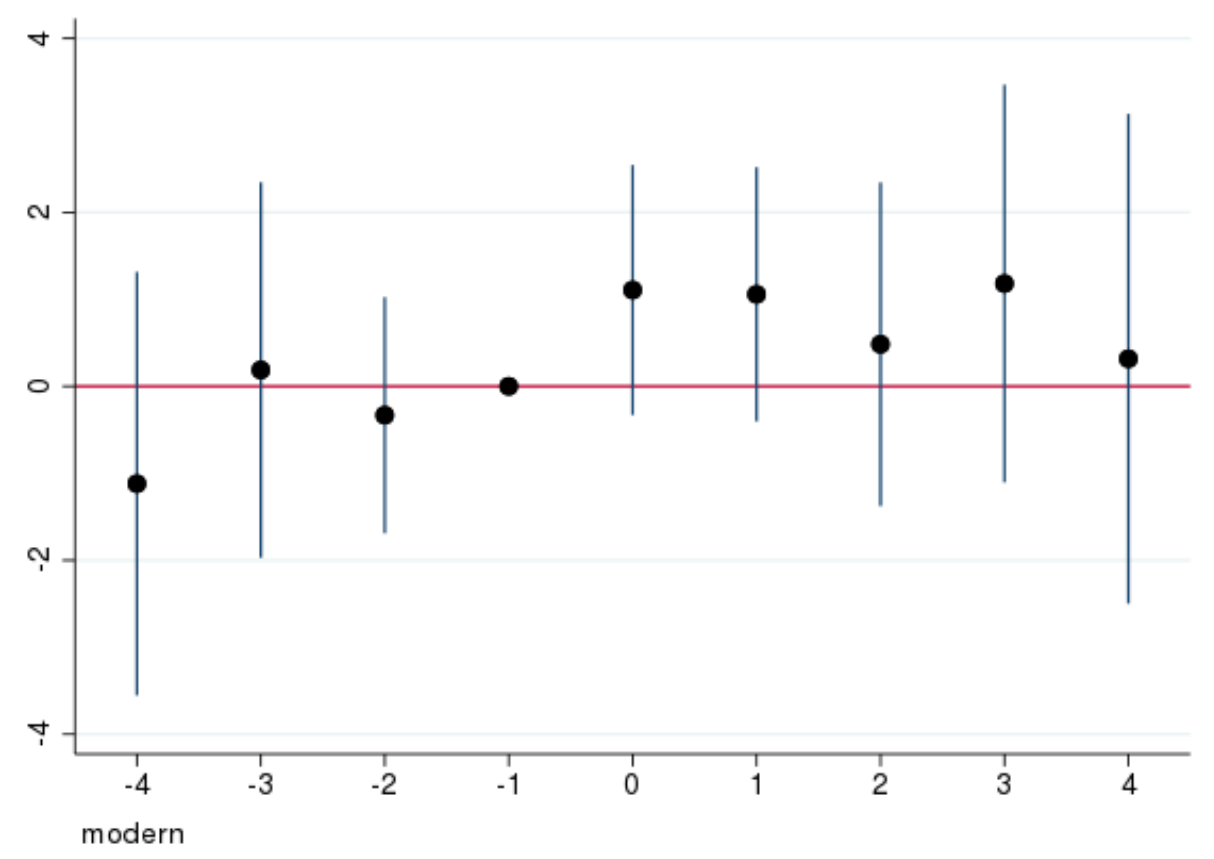

B. Pill Mill

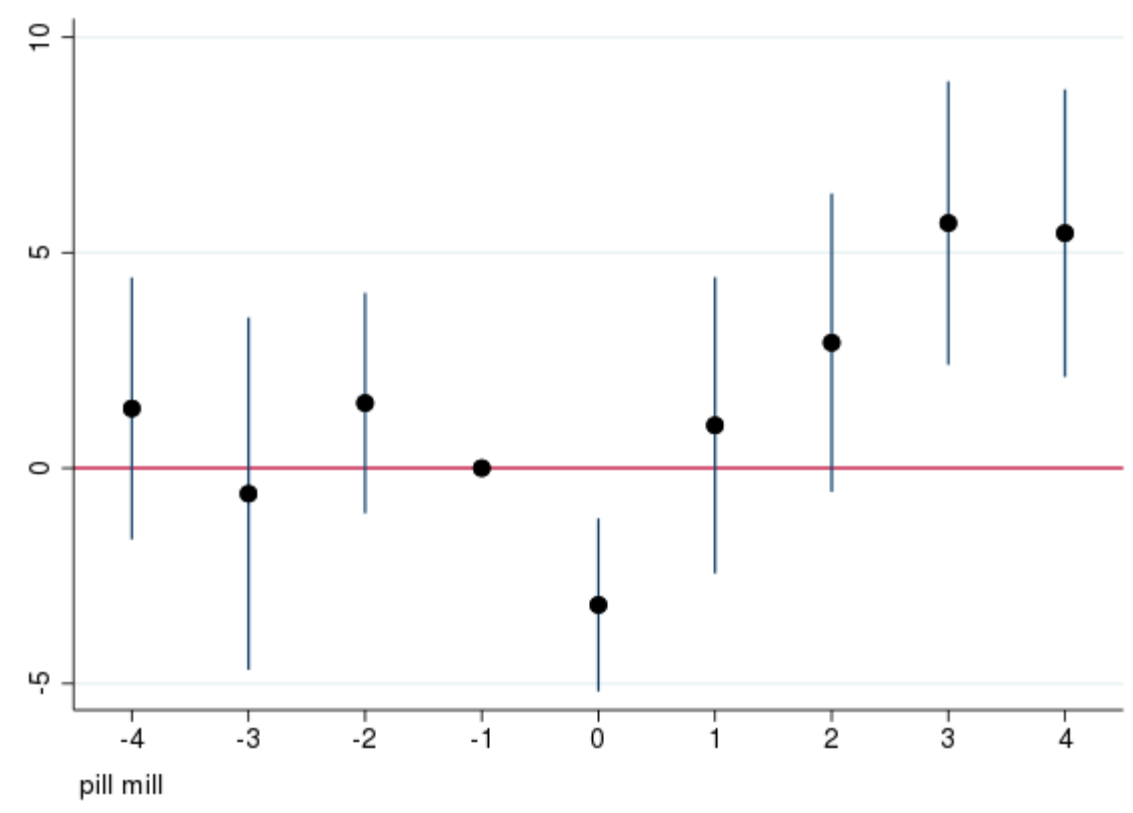


Figure 5: Event Study Coefficients of the Modern Prescription Drug Monitoring Program (PDMP) and Pill Mill Laws on Prenatal Care Beginning in the First Trimester 2002-2016

A. Modern PDMP

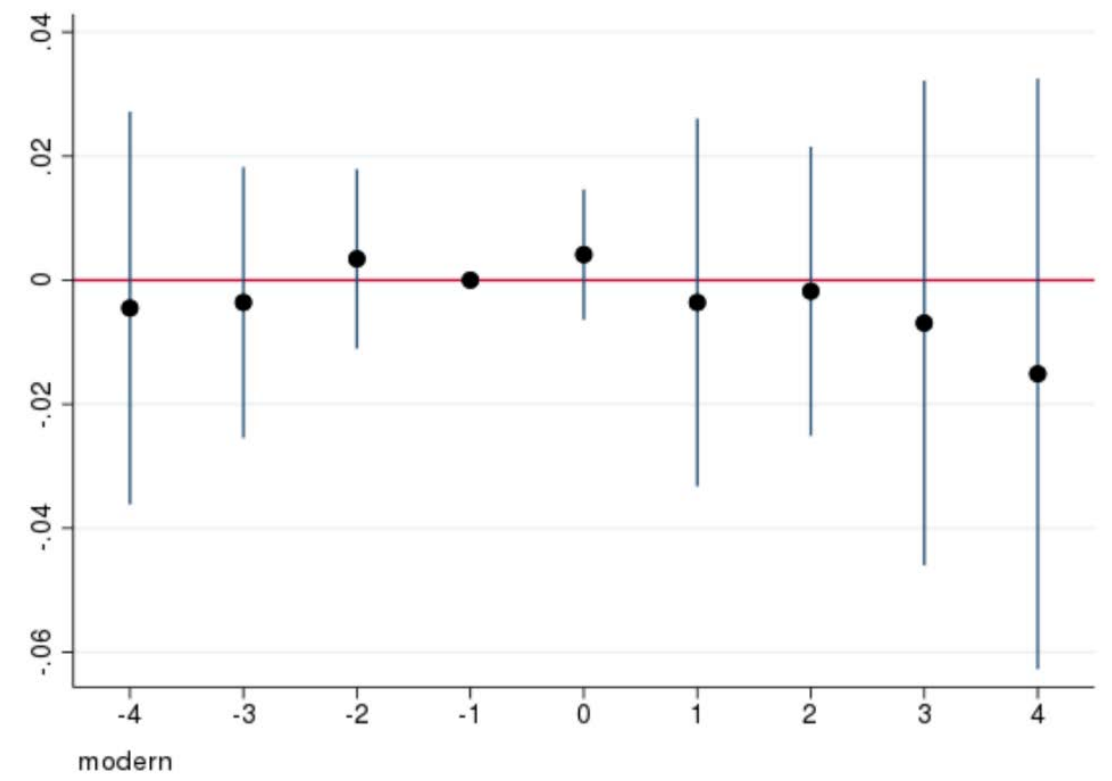

B. Pill Mill

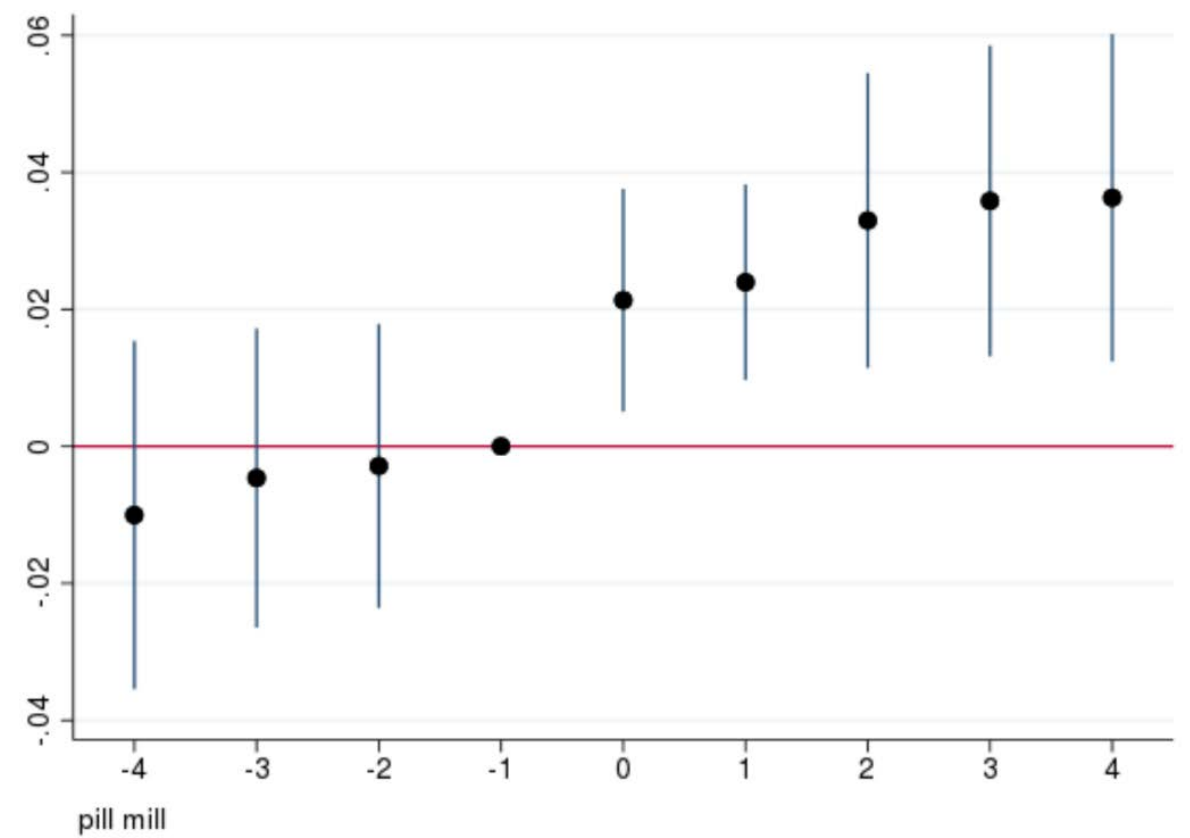


Figure 6: Event Study Coefficients of the Modern Prescription Drug Monitoring Program (PDMP) and Pill Mill Laws on Inadequate Prenatal Care Visits 2002-2016

A. Modern PDMP

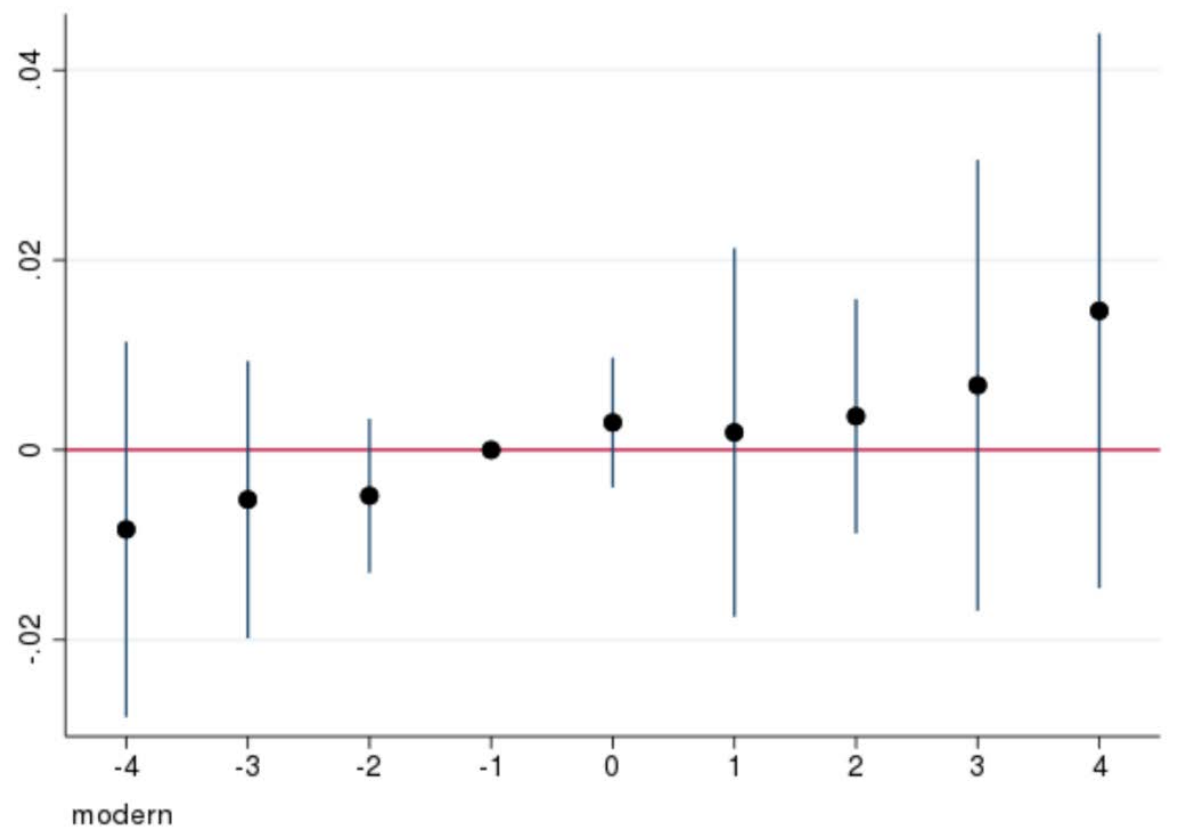

B. Pill Mill

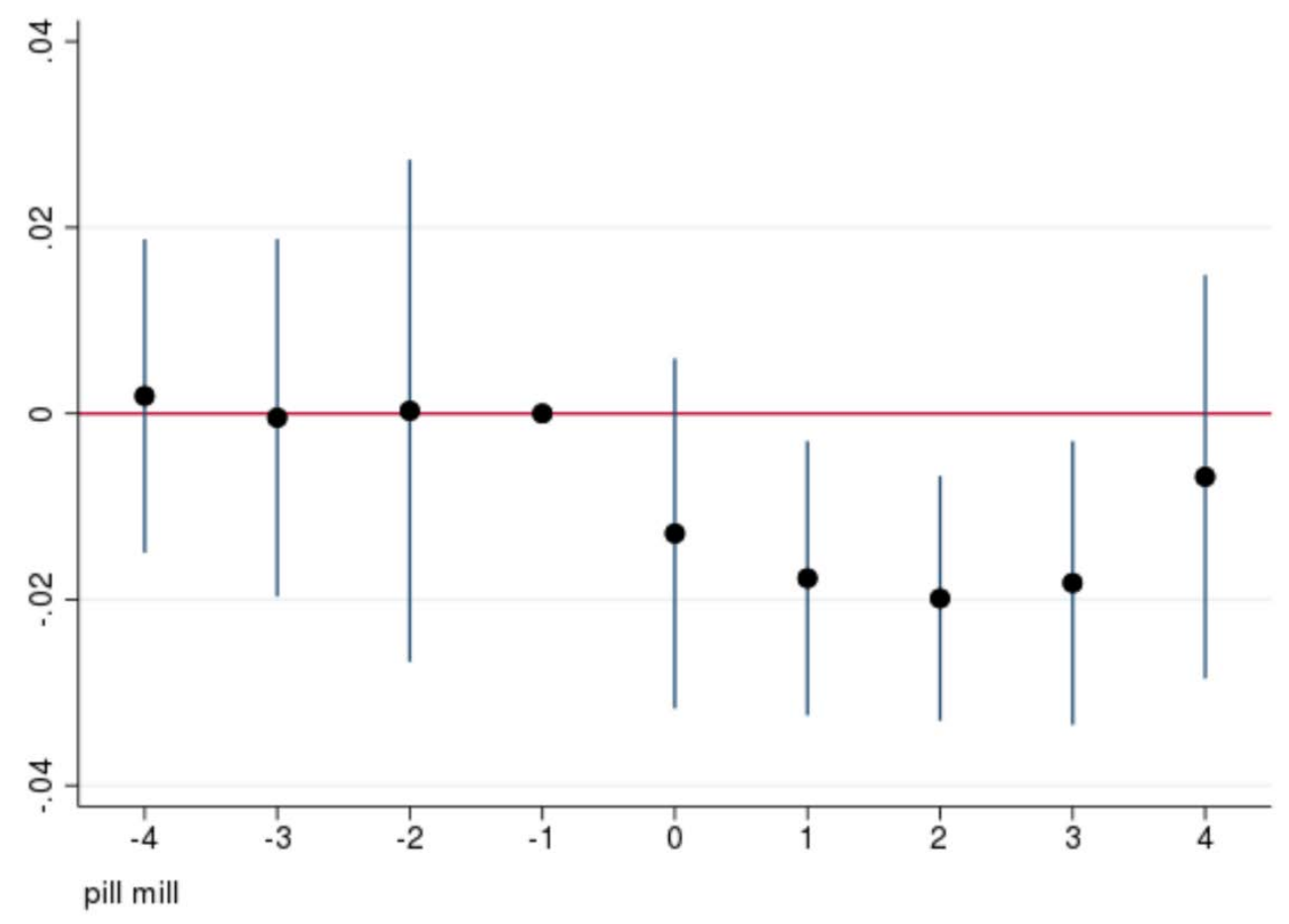

